\title{
El juego de las Entidades supramunicipales en España. Algunas reflexiones en el décimo aniversario de la Ley de Régimen Local de 2 de abril de 1985
}

\author{
M. ${ }^{a}$ Concepción Barrero Rodríguez \\ Profesora Titular de Derecho Administrativo \\ Universidad de Sevilla
}

Sumario: I. PLANTEAMIENTO. II. LA COMARCA, UNA ADMINISTRACIÓN DE MARCADA VOCACIÓN TERRITORIAL: 1. Las claves de la Comarca en la Ley Básica de Régimen Local. 2. La Comarca en el Derecho autonómico. Su clara decantación en favor de la opción territorial. A. La Comarca en los Estatutos de Autonomía. B. La Comarca en la Legislación autonómica. 3. Conclusiones. La configuración definitiva de la Comarca como Administración territorial. Su difícil articulación. III. LAS MANCOMUNIDADES DE MUNICIPIOS, LA FÓRMULA NATURAL DE PRESTACIÓN DE SERVICIOS MUNICIPALES EN NUESTRO DERECHO. 1. La regulación de las Mancomunidades en la Ley de Régimen Local de 1985. Sus rasgos distintivos. 2. El desarrollo e implantación de las Mancomunidades en el ordenamiento autonómico. 3. Valoración. La Mancomunidad de nuestro tiempo. ¿Una pérdida del sentido de la figura conforme a su regulación en la LBRL? IV. LAS ÁREAS METROPOLITANAS, LA POSIBILIDAD DE MODELOS ALTERNATIVOS. 1. La Ley Básica de Régimen Local y su profunda indefinición en relación con las Áreas metropolitanas. 2. La diversidad del Derecho autonómico sobre Áreas metropolitanas. A. La opción cuasi territorial del Área metropolitana de La Huerta. B. El modelo institucional del Área de Barcelona. C. La realidad metropolitana en otras Comunidades Autónomas. 3. La valoración del sistema. La falta de institucionalización del nivel de gobierno metropolitano. Las soluciones paralelas. V. REFLEXIÓN FINAL.

\section{PLANTEAmiento}

Las Entidades supramunicipales en nuestro país siguen constituyendo, a pesar del tiempo transcurrido desde el inicio de la reforma del Régimen local, un foco de permanente actualidad. Las ilusiones concitadas por la planta territorial sentada por la Constitución de 1978 se 
verían pronto defraudadas en su escalón local. Las Entidades diseñadas por el nuevo Derecho para el gobierno y administración de aquellos espacios en los que la escala municipal resulta insuficiente para la satisfacción de los intereses propios de su población, no han dado, hasta ahora, los frutos esperados, pudiendo afirmarse, con toda justicia, que la vertebración de un nivel supramunicipal, realmente ajustado a las necesidades públicas, se erige en la gran asignatura pendiente de la organización territorial en nuestro país; de ahí que no resulte ociosa una nueva reflexión sobre las Entidades supramunicipales en nuestro Derecho.

Son muchos los sistemas de gobierno supramunicipal que el ordenamiento de diferentes países, y también el nuestro, ha conocido en su evolución histórica. A grandes rasgos, pudieran distinguirse tres grandes modelos. De un lado, aquel que se asienta en fórmulas de colaboración entre los Municipios asentados en un mismo ámbito territorial; de otro, el que, en aras de una auténtica organización unitaria de gobierno en un espacio de rasgos físicos homogéneos y necesidades comunes, suprime la red municipal existente integrando a todos los Municipios en un nuevo ente. Finalmente, y entre ambos polos, una solución ecléctica o intermedia que, a la vez que satisface las exigencias de una organización supramunicipal con la creación de un nuevo ente, mantiene el entramado de Administraciones locales básicas presentes en el territorio. Un modelo, el más frecuente por lo demás, en el que pueden ser aislados, a su vez, varios sistemas alternativos, toda vez que la naturaleza y características de la Entidad creada pueden ser muy diversas. En algunos supuestos, responden a los esquemas propios de las Administraciones territoriales; en otros, a los moldes característicos de los entes institucionales con la variada tipología que éstos, por su parte, pueden revestir. En otras ocasiones, incluso, podrán acomodarse a los esquemas típicos de las empresas públicas en sus diversas manifestaciones.

De casi todos esos modelos tenemos precedentes en la historia normativa española; todos esos modelos pueden hacerse realidad en el Derecho vigente. La LBRL, de conformidad con las amplias posibilidades abiertas en tal sentido por la Constitución -artículos 141.3 y $152.3^{1}$ ha establecido un marco sumamente flexible en el que no sólo se hacen

\footnotetext{
1 Conforme al primero, «se podrán crear agrupaciones de Municipios diferentes de la provincia». En aplicación del segundo, «mediante agrupaciones de municipios limítrofes, los Estatutos podrán establecer circunscripciones territoriales propias que gozarán de plena personalidad jurídica».

Para un examen de dichos preceptos constitucionales, me remito al estudio de R. GOMEZFERRER MORANT "El encaje constitucional de la Administración metropolitana» (DA, $\mathrm{n}$. 188,1979 , págs. 395 y ss.).
} 
posibles diversos sistemas de gestión supramunicipal, sino en el que, además, una misma Entidad puede adquirir plasmaciones diferentes en función de la propia realidad de cada Comunidad autónoma y de las opciones que inspiren su organización territorial. Nos hallamos, en definitiva, en un mundo presidido por un principio de diversidad, predicable, no sólo, de la comparación de estas Entidades entre sí, sino extensible, en algunos casos, al corazón mismo de cada una de ellas.

El estudio que aquí abordo no tiene por objeto el análisis de todas y cada una de esas fórmulas, ni tan siquiera el más exhaustivo de alguna de ellas; se sitúa en una clave distinta. Pretende simplemente ofrecer una impronta del juego dado, a los más de quince años de vigencia de la Constitución de 1978, por las Entidades supramunicipales contempladas en la Ley de Bases del Régimen Local de 2 de abril de 1985 (LBRL) y posteriormente desarrolladas por el Derecho autonómico: las Comarcas, Mancomunidades de Municipios y Áreas metropolitanas. Más concretamente, me interesa determinar cuál es la naturaleza y el papel que a cada una de ellas asigna la LBRL, para, en un momento posterior, analizar, desde esas coordenadas, el ordenamiento y la acción desarrollada en este ámbito por las Comunidades Autónomas. En términos más concretos, este estudio quiere responder a la siguiente pregunta, ¿vale cualquier Entidad para el ejercicio de cualquier competencia supramunicipal o existe, por el contrario, en la Ley de 1985 una adscripción de cada una de ellas al desempeño de un papel determinado?

El interés concitado por esta pregunta nace, a mi juicio, de la cierta discordancia que la realidad parece mostrar entre el sentido y la funcionalidad otorgada a cada una de estas Administraciones por la legislación básica del Estado y el uso que de ellas viene haciéndose, con amparo incluso, en algunas ocasiones, en su propio Derecho, por las Comunidades Autónomas. De una parte, las Mancomunidades de Municipios, las verdaderas y auténticas protagonistas de la supramunicipalidad hoy en España, pudieran estar abandonando su sentido genuino de Entidades adscritas a la ejecución de obras o la prestación de servicios de origen, en todo caso, municipal, para convertirse en una instancia de más amplio calado que podría venir, en determinados supuestos, a suplantar el papel asignado a otra institución distinta: la Comarca, Entidad que no termina de encajar en nuestra actual planta territorial. Las Áreas metropolitanas de otra parte, respuesta de la LBRL a los problemas de las grandes aglomeraciones urbanas, no han sabido cumplir con los objetivos que la Ley de 1985 les asigna. La equivalencia intereses metropolitanos/Areas metropolitanas dista mucho de ser lograda. Las Comunidades Autónomas ofrecen hoy una amplia gama de 
fórmulas variadas para el gobierno de las zonas metropolitanas, desde la que puede llegar a afirmarse que el Área Metropolitana constituye hoy un remedio excepcional de resolución de los intereses propios de los espacios de esta naturaleza. Por último, la realidad de nuestro tiempo muestra una auténtica proliferación de vías de satisfacción de intereses supramunicipales al margen de las Entidades descritas. Los Consorcios - figura de naturaleza debatida y polémica, dada su confusa regulación legal 2-, las sociedades públicas mixtas ${ }^{3} \mathrm{e}$, incluso, simples convenios de cooperación entre las Administraciones afectadas 4 se encuentran entre las de uso más frecuente.

Puede, en definitiva, hablarse de la existencia de una cierta perversión en el uso de las Entidades supramunicipales conforme a su diseño en la LBRL, marco de obligado respeto por las Comunidades Autónomas en el ejercicio de sus poderes normativos en este ámbito ${ }^{5}$. La fun-

2 Para un mayor análisis de esta figura, me remito a los estudios contenidos en la obra Consorcios Locales (Ed. CEMCI, en prensa).

${ }^{3}$ La mejor prueba de esta afirmación nos la ofrece el artículo 38 de la Ley de Demarcación Municipal de Andalucía en el que se afirma: "Podrán constituirse Sociedades para fines de interés público bajo la forma de Sociedad mercantil con la participación de capital público de una o varias Administraciones Públicas y, en su caso, de capital privado".

Es amplia y rica la bibliografía que se ha ocupado del estudio de la prestación de servicios públicos locales a través de formas de Derecho privado, desde la clásica obra de $\mathrm{F}$. AlBI, Tratado de los modos de gestión de las Corporaciones Locales (Ed. Aguilar, 1960). A título puramente ejemplificativo y, entre otros, puede citarse ALCOVER GARAU ("Aproximación al régimen jurídico de la sociedad de capital local", $R A P$, n. $^{\circ} 134,1994$, págs. 78 y ss.); Alonso UREBa (La empresa pública. Aspectos jurídico-constitucionales y Derecho económico, Ed. Montecorvo, 1985, y La sociedad mercantil de capital como forma de la empresa pública local, Ed. Universidad Complutense, 1988); DuOue Dominguez ( $«$ La sociedad privada municipal», REVL, n. ${ }^{\circ} 179,1973$ ); MARTí MATEO («Los servicios locales. Especial referencia a la prestación bajo fórmulas societarias", REALA, 255-6, 1992, págs. 475 y ss.); F. SOSA WAGNER (La gestión de los servicios públicos locales, Ed. Civitas, 1992, págs. 65 y ss.) y TENA PiAzuelo («La empresa pública local: aspectos jurídico-formales de la gestión municipal de intereses económicos mediante sociedad anónima», REALA, n. ${ }^{\circ}$ 255-6, 1992, págs. 701 y ss.).

${ }^{4} \mathrm{Me}$ remito al respecto a las consideraciones efectuadas por F. LÓPEZ MENUdo en «Servicios municipales y gestión consorciada" (Los consorcios... ob. cit.).

5 Recordar que en aplicación de los criterios que rigen la distribución de competencias entre el Estado y las Comunidades Autónomas en materia de Régimen local, puede afirmarse que la regulación de las Entidades supramunicipales ha quedado básicamente en manos de los Parlamentos autonómicos. Son Entidades, en palabras del Tribunal Constitucional - Sentencia 214/1989 - con un fuerte grado de interiorización autonómica, en el sentido de que son las Comunidades Autónomas «las encargadas de determinar y fijar las competencias de las Entidades locales que procedan a crear en sus respectivos ámbitos territoriales". 
damentación de esta afirmación da razón de ser a este estudio que voy a estructurar en dos partes: la exposición del Derecho sobre cada una de esas Administraciones y una reflexión final en la que intentaré levantar acta del estado actual de la cuestión supramunicipal en España a partir de los datos ofrecidos por su regulación y la experiencia de no pocos años, ya, de vida constitucional.

\section{LA COMARCA, UNA ADMINISTRACIÓN DE MARCADA VOCA- CIÓN TERRITORIAL}

La naturaleza compartida de las competencias normativas para la regulación de la Comarca, obliga a plantear su estudio en dos tramos diferentes: el estatal y el autonómico.

\section{Las claves de la Comarca en la Ley Básica de Régimen Local}

«1. Las Comunidades Autónomas, de acuerdo con lo dispuesto en sus respectivos Estatutos, podrán crear en su territorio Comarcas $u$ otras entidades que agrupen varios Municipios, cuyas características determinen intereses comunes precisados de una gestión propia o demanden la prestación de servicios de dicho ámbito.

2. La iniciativa para la creación de una Comarca podrá partir de los propios Municipios interesados. En cualquier caso, no podrá crearse la Comarca si a ello se oponen expresamente las dos quintas partes de los Municipios que debieran agruparse en ella, siempre que, en este caso, tales Municipios representen al menos la mitad del censo electoral del territorio correspondiente. Cuando la Comarca deba agrupar a Municipios de más de una Provincia, será necesario el informe favorable de las Diputaciones provinciales a cuyo ámbito pertenezcan tales Municipios.

3. Las leyes de las Comunidades Autónomas determinarán el ámbito territorial de las Comarcas, la composición y el funcionamiento de sus órganos de gobierno, que serán representativos de los Ayuntamientos que agrupen, así como de las competencias y recursos económicos que, en todo caso, se les asignen.

4. La creación de las Comarcas no podrá suponer la pérdida de los Municipios de la competencia para prestar los servicios enumerados en el artículo 26, ni privar a los mismos de toda intervención en cada una de las materias enumeradas en el apartado 2 del artículo 25.» 
Una idea fundamental cabe extraer de esta regulación contenida en su artículo 42: la LBRL, a pesar de lo dispuesto en su artículo tercero - precepto del que parece inferirse el carácter no territorial de toda Administración Local distinta de Municipios o Provincias-, no prejuzga la naturaleza jurídica de esta Entidad ${ }^{6}$. Crea, más bien, el marco dentro del cual le es lícita a las Comunidades Autónomas la opción por unos u otros diseños comarcales en función de su trayectoria histórica, sus propias convicciones sobre la organización de su territorio y las necesidades a las que con esta Administración pretendan dar respuesta. La adopción por la LBRL de este modelo comarcal abierto, no impide, sin embargo, intuir en ella una cierta decantación por una Comarca de marcada vocación territorial. Argumentos de diversa índole alimentan esta aseveración:

a) En primer término, su propia definición como Entidad que agrupa a varios Municipios "cuyas características determinen intereses comunes precisados de una gestión propia o demanden la prestación de servicios de dicho ámbito». "Una comunidad de intereses», claro sustrato de las Administraciones de signo territorial y «necesidad de una gestión propia o prestación de servicios», referencia a un conjunto de competencias múltiples con engarce directo en las necesidades de este grupo poblacional que le sirve de sustento.

b) En segundo lugar, el sistema de garantías que la propia Ley, artículo 42.4, articula en beneficio de las competencias municipales - «la creación de las Comarcas no podrá suponer la pérdida por los Munici-

\footnotetext{
${ }^{6}$ En tal sentido, T. Font I LLOVET ( «La Comarca y las estructuras del Gobierno local». La Provincia en el sistema constitucional. Ed. Civitas-Diputación de Barcelona, pág. 277).

De esta indeterminación en la que la Comarca ha quedado en la LBRL da buena cuenta la disparidad de juicios que ha merecido la calificación de su naturaleza jurídica. Así, J. L. RIVERo ISERN se inclina por una configuración no territorial de esta Entidad (Manual de Derecho Local, Ed. Junta de Andalucía, 1989, pág. 166), en el mismo sentido que R. MarTin Mateo (Entes locales complejos, Ed. Trivium 1987, págs. 168 y ss.) o T. FonT I LLOVET, aun reconociendo cómo, en último término, la decisión ha quedado en manos del legislador autonómico ("Perspectivas de organización supramunicipal», Autonomies, n. ${ }^{\circ} 1,1985$, págs. 64 y 65). Para F. LLISET BorRell, y de acuerdo con su calificación por la ley autonómica, puede ser indistintamente «una Entidad territorial con fines genéricos o una Entidad institucional para fines específicos" (Manual de Derecho local, Ed. Abella 1985, pág. 193), criterio compartido por A. SÁnCHEZ BLANCo ("La Comarca como factor de coherencia regional», RAP n. ${ }^{\circ} 90,1979$ pág. 30); R. ENTRENA CuESTA (“La Comarca. La Comarca y la Administración territorial", Temas de Administración Local, n. ${ }^{\circ} 18,1986$, pág. 62); E. RocA RoCA («La Comarca y los Estatutos de autonomía». La comarca, ob. cit., pág. 126) y L. MORELL OCAÑa (El Régimen Local español, Ed. Civitas, 1988, pág. 30).
} 
pios de la competencia para prestar los servicios enumerados en el artículo 26, ni privar a los mismos de todo tipo de intervención en las materias enumeradas en el apartado 2 del artículo 25 "-, de donde cabe inferir que en la mente del legislador la creación de una Entidad de este género constituye una operación ligada a un amplio proceso de reajuste de competencias entre las diferentes Administraciones desplegadas en el territorio que haya de servirle de base.

c) La exigencia de Ley para su creación viene, desde otra perspectiva, a abundar en esta misma idea. La citada reserva legal sólo tiene sentido desde unas coordenadas de redistribución del poder de más amplio alcance que el de una mera traslación de competencias municipales a la Entidad creada.

d) Que la Comarca es o debe ser algo más que un ente para la prestación de un servicio o la ejecución de una obra determinada es algo que se corrobora, igualmente, en la existencia en la propia LBRL de otra figura diseñada con ese fin específico y de más fácil articulación: la Mancomunidad de Municipios. ¿Qué sentido tendría, ante necesidades de ese carácter, acudir a los lentos y complicados trámites de constitución de una Comarca cuando la propia norma jurídica brinda otro instrumento de más fácil realización?; ¿para qué poner en marcha todo un proceso legislativo cuando bastaría el simple acuerdo de los Municipios afectados para operar esa pretendida prestación supramunicipal de un servicio?

e) No parecieron quedarle dudas tampoco al Tribunal Constitucional en el sentido de que la LBRL, con apoyo en los artículos 141.3 y $152.3 \mathrm{CE}$, ampara la creación de nuevos Entes de naturaleza territorial. Así, en su Sentencia 214/1989, y en relación precisamente con la Comarca, cuya regulación en la Ley de 1985 se enjuiciaba, pudo afirmar que «la aparición de nuevos entes territoriales ha de tener una profunda repercusión sobre la delimitación de cuál sea el interés propio de las hasta ahora existentes y, en consecuencia, sobre su ámbito competencial».

f) Tampoco el Ministerio para las Administraciones Públicas se ha cuestionado, en un reciente Informe, sobre la calificación territorial de la Comarca. Así, y saliendo al paso de la cierta confusión creada en torno a las diferencias que separan a esta Entidad de la Mancomunidad de Municipios, ha podido afirmar: «esa pretendida incompatibilidad entre ambas instituciones, solamente será posible si desnaturalizamos 
la Comarca, si prescindimos de su ratio fundamental, el ser circunscripción territorial de la propia Comunidad Autónoma...» 7.

En definitiva, en la LBRL, y a pesar de la parquedad de su regulación, existen indicios que avalan de forma suficiente, a mi juicio, la afirmación de que la opción comarcal que en ella subyace es la de una Administración de innegable vocación territorial.

\section{La Comarca en el Derecho autonómico. Su clara decantación en favor de la opción territorial}

Centrados en este ámbito, pueden, a su vez, distinguirse en el análisis dos partes claramente diferenciadas. En primer término, el examen de esta Entidad en los diferentes Estatutos de Autonomía; en segundo lugar, su estudio en la legislación autonómica dictada hasta la fecha.

\section{A. La Comarca en los Estatutos de Autonomía}

Del análisis del conjunto de previsiones estatutarias sobre esta Entidad, pueden destacarse, no obstante su disparidad, las siguientes ideas básicas.

a) Su generalizada presencia en los Estatutos de Autonomía, si bien no siempre con el mismo carácter. Hay Comunidades Autónomas que, desde su propia Norma fundamental, han apostado ya por una Administración comarcal de carácter necesario, pieza básica, por consecuencia, de su organización territorial. Es el caso de las Comunidades de Cataluña, Valencia, La Rioja, Murcia o el Principado de Asturias 8; otras, las más, se limitan, por el contrario, a prever su constitución dejando en manos del legislador autonómico la decisión acerca de su implantación, así

7 Las Mancomunidades Intermunicipales en el Régimen Local Español (Ed. MAP, 1994, págs. 24 y 25).

${ }^{8}$ El Estatuto de la Comunidad de Cataluña prevé en su artículo 5.1 que "La Generalidad de Cataluña estructurará su organización territorial en Municipios y Comarcasn; el del Principado de Asturias, artículo 6.1, que la citada Comunidad se organiza "territorialmente en Municipios, que recibirán la denominación tradicional de Concejos, y en Comarcas»; el 5 del Estatuto de la Comunidad de La Rioja afirma que su "organización territorial se estructurará en Municipios y Comarcas"; en tanto que el 3.1 de la Comunidad de Murcia establece que su territorio "se organiza en Municipios y Comarcas o agrupaciones de Municipios limítrofes, basadas en criterios históricos, naturales, geograficos, socioeconómicos, culturales o demograficos"... Significativa también, dentro de este mismo grupo, es la Norma básica de la Comunidad valenciana, conforme a la cual y a tenor de su artículo 46, una Ley de su Parlamento, por mayoría absoluta, "determinará la división comarcal, oidas las Corporaciones locales afectadas". 
como la delimitación de aquellos rasgos que definitivamente hayan de definirla. La Comarca no contaría aquí - como en el caso anterior-con una garantía estatutaria, lo que sitúa a los Parlamentos de las Comunidades Autónomas ante más amplias cotas de libertad a la hora de optar por uno u otro modelo de Administración comarcal, si finalmente se decantan por una instauración de esta instancia en su territorio. Es la línea en la que se inscriben Comunidades como las de Andalucía, Galicia, Cantabria, Aragón, Castilla-La Mancha, Extremadura o Castilla y León ${ }^{9}$. Como tercer grupo, finalmente, puede aislarse el representado por la $\mathrm{Co}-$ munidad del País Vasco, en donde la Comarca, a la que no se menciona expresamente, puede hallar, sin embargo, cobijo en aquella previsión estatutaria que contempla las agrupaciones de Municipios diferentes de la Provincia. El resultado práctico, en este caso, viene a ser el mismo que en la hipótesis anterior: la Administración comarcal será el fruto de la voluntad del legislador autonómico al que corresponde proceder a su creación, así como determinar sus concretos caracteres ${ }^{10}$.

b) La generalización o no de un debido o eventual proceso comarcal constituye la segunda gran nota distintiva de los Estatutos de Autonomía en su regulación de esta Entidad. Hay Comunidades Autónomas en las que, por mandato estatutario, un necesario o posible proyecto de comarcalización ha de comprender todo su ámbito territorial. No cabe la Comarca como Entidad aislada, respuesta a las necesidades puntua-

\footnotetext{
${ }^{9} \mathrm{El}$ artículo 5 de la Norma andaluza establece que "por Ley del Parlamento andaluz podra regularse la creación de Comarcas integradas por Municipios limitrofes dentro de la misma Provincia, atendiendo a sus características geográficas, económicas, sociales e historicas...». Por su parte, el artículo 27 del Estatuto de Galicia señala que por Ley de su Parlamento se podrá "reconocer la Comarca como Entidad local con personalidad jurídica y demarcación propia», en parecidos términos al Estatuto de Cantabria que proclama que por Ley «se podrá reconocer a la Comarca dentro de cada Provincia como Entidad local con personalidad jurídica y demarcación propia». Una línea en la que también se inscribe la Comunidad aragonesa: "Una ley de las Cortes de Aragón - afirma el artículo 5 de su Estatuto-podrá ordenar la constitución y regulación de las Comarcas"; de la misma forma que sucede en la Comunidad de Castilla-La Mancha "Por Ley —artículo 29.2 de su Estatuto- se podrá reconocer la Comarca dentro de cada Provincia como Entidad local con personalidad jurtdica y demarcación propia" o en la de Extremadura, cuyo artículo 2.1 prevé, igualmente, que por Ley de su Parlamento se estructure su organización en Comarcas. Lo mismo ocurre en la Comunidad de Castilla y León. Así dice el artículo 19.3 de su Estatuto: "Por las correspondientes Leyes de Cortes de Castilla y León, específicas para cada supuesto, se podrán reconocer Comarcas, mediante la agrupación de Municipios limítrofes, atendiendo al informe previo de los Municipios afectados y a sus características geográficas, económicas, sociales e historicas para la gestión en común de servicios o la colaboración en el ejercicio de sus competencias".
}

10 El artículo 37.1 del Estatuto del País Vasco señala la competencia exclusiva del Parlamento de esta Comunidad sobre "demarcaciones territoriales de ámbito supramunicipal que no excedan de la Provincia». 
les de concretos espacios; un carácter que es, precisamente, el que asume en otras Comunidades autónomas. En el primer grupo se encuadra Cataluña que «estructurará su organización territorial en Municipios y Comarcas» o el Principado de Asturias que se vertebra, igualmente, "en Municipios... y en Comarcas» 11; en el segundo, las Comunidades, por ejemplo, de Andalucía, Galicia o Cantabria.

No puede hablarse, en síntesis, de uniformidad estatutaria en la regulación de la Entidad Comarcal. Hay Comunidades Autónomas respecto de las que pocas dudas pueden quedar acerca de la naturaleza territorial de la Entidad que crean. Son, por lo general, aquellas que, como Cataluña, la configuran como pieza básica de su organización territorial 12; en la mayoría, en cambio, esta Administración se presenta con elevadas dosis de indeterminación. Por encima de su condición de Entidad local nacida de una agrupación de Municipios, poco o nada se dice de ellas. Existen, no obstante, dos notas, continuamente repetidas en los distintos Estatutos, que pueden llevar a pensar que para el legislador estatutario, lo mismo que para el de la LBRL, la Comarca constituye una Entidad de marcado corte territorial. De una parte, la continua alusión que en muchas de esas normas se produce al sustrato de la Comarca como "agrupación de Municipios limítrofes de características geográficas, económicas, sociales e históricas uniformes» 13; referencia, en suma, a una colectividad local dotada de una sustantividad propia y portadora, por consiguiente, de unos intereses peculiares que justificarían la creación de un ente destinado a su gestión; de otra, y al igual que ocurre en la LBRL, la previsión de otras agrupaciones de Municipios para fines específicos, a las que expresamente definen muchos Estatutos por su

\footnotetext{
11 En este mismo grupo deben de incluirse, igualmente, las Comunidades de Murcia, La Rioja y Valencia.

$12 \mathrm{El}$ artículo 5.1 de su Estatuto es bien significativo a este respecto: «La Generalidad de Cataluña estructurará su organización territorial en municipios y comarcas». Una naturaleza territorial que queda realzada, interpretando, sensu contrario, el párrafo segundo del citado precepto, donde se prevé la creación de entes de naturaleza institucional, "agrupaciones basadas en hechos urbanisticos y metropolitanos y otros de carácter funcional y fines específicos". No le habían quedado tampoco dudas a la doctrina acerca de la naturaleza territorial de la Comarca en Cataluña. En tal sentido, PRATS I CATALA («La Comarca», Tratado de Derecho municipal. Obra dirigida por S. MuÑz MaCHADo, Ed Civitas 1988. Vol. I, pág. 824) y R. ENTRENA Cuesta («La Comarca. La Comarca y la Administración territorial „...,ob. cit., pág. 58). La legislación dictada en desarrollo del Estatuto terminaría por confirmar esa impresión.
}

$13 \mathrm{Tal}$ nota, como rasgo sustantivo de la Comarca, aparece, por ejemplo, en los Estatutos de Andalucía (artículo 5); Murcia (artículo 3.1) y Castilla y León (artículo 19.3). 
EL. JUEGO DE LAS ENTIDADES SUPRAMUNICIPALES EN ESPAÑA

«carácter funcional»14. Si la Comarca fuese un ente instrumental para la prestación de un servicio concreto, ¿qué sentido tendría su inclusión expresa en aquellos textos estatutarios que ya prevén de forma genérica la creación de Entidades basadas en una asociación de Municipios?

\section{B. La Comarca en la Legislación autonómica}

No son muchas, ciertamente, las Comunidades que disponen de regulaciones de la Comarca; de ahí que las conclusiones que aquí puedan extraerse deban siempre ser relativizadas en espera de su contraste con futuras normativas.

a) La Ley 3/1986, de 15 de mayo, del Principado de Asturias. Una norma sobre procedimiento, su falta de aplicación.

Fue la Comunidad del Principado de Asturias la primera en contar con una regulación de esta Entidad: la establecida en la Ley 3/1986, de 15 de mayo. No es mucho lo que, en contra de la apariencia, aporta esta Ley. Constituye una simple norma de fijación del procedimiento de creación de Comarcas. Sus competencias concretas, organización y régimen de funcionamiento son cuestiones que quedan diferidas a las Leyes de constitución de cada Entidad.

La falta de creación de Comarcas en ese territorio, a los casi diez años de vigencia de la disposición que analizo, impide realizar otro comentario que no sea el de una llamada de atención sobre el llamativo contraste que se produce entre el extraordinario valor que el Estatuto del Principado de Asturias otorga a esta Entidad -artículo 6- y la posterior atonía de las Instituciones de la Comunidad Autónoma en la implantación efectiva de dicha instancia. Las Mancomunidades de Municipios, que alcanzan la cifra total de doce, nueve de ellas creadas con posterioridad a la Ley que comento ${ }^{15}$, le han ganado abiertamente la partida. Unas Mancomunidades dotadas, a excepción de algunas

\footnotetext{
14 Así ocurre en los Estatutos de Cataluña (artículo 5), Galicia (artículo 20), Cantabria (artículo 36), La Rioja (artículos 5 y 9.1), Murcia (artículo 3), Castilla-La Mancha (artículo 29), Extremadura (artículo 2) y Castilla y León (artículo 19.3).

${ }^{15}$ Me sirvo en este estudio de los datos ofrecidos por el Ministerio para las Administraciones Públicas actualizados al 28 de febrero de 1994 (Las Mancomunidades Intermunicipales en el Régimen Local español, Ed. MAP, 1994).
} 
de ellas ${ }^{16}$, de un amplio abanico de fines - servicios sociales, culturales, sanitarios, agropecuarios, turísticos, obras públicas, oficina técnica de gestión y coordinación urbanística y medio ambiente, centro de asistencia a la mujer, etc. ${ }^{17}$ - desde las que viene a hacerse, quizá, superflua la instauración del nivel comarcal. Más adelante abundaré en esta idea.

\section{b) La opción comarcal en Cataluña}

Una situación bien diferente es la que ofrece la Comunidad catalana. La previsión estatutaria favorable a una Comarca de carácter necesario y naturaleza territorial, hallaría fiel reflejo en el conjunto de leyes reguladoras del Régimen local en Cataluña, aprobadas en abril de 1987. El artículo 3..$^{\circ}$ de la Ley 8/1987 de 15 de abril, de Administración local, no duda en calificar a la citada Entidad como «Administración territorial», atribuyéndole autonomía para la gestión de sus respectivos intereses, así como el conjunto de potestades propias de los Entes locales de esta naturaleza. Pocos días antes, la Ley 6/1987, de 4 de abril, de Comarcas, la había ya definido como "Entidad local de carácter territorial formada por la agrupación de Municipios contiguos», dotada de "personalidad jurídica propia y plena capacidad y autonomía para el cumplimiento de sus fines" 18 . La Comarca se constituye así abiertamente en cauce para el ejercicio de competencias de muy diversa naturaleza y origen, como lo prueban los artículos 25 y 26 de la Ley de 4 de abril. «La Comarca - afirma el primero de ellos- ejercerá las competencias que le atribuyan las leyes del Parlamento, las cuales, en cualquier caso, le otorgarán competencias sobre las siguientes materias: ordenación del territorio y urbanismo, sanidad, servicios sociales, cultura, deporte, enseñanza, salubridad pública y medio ambiente»; el segundo, especifica, por su parte, las competencias comarcales en relación con las locales: «establecer y prestar los servicios mínimos en caso

\footnotetext{
16 Por ejemplo, la de Grado y Yernes-Tameza que tiene por fin estatutario "parque maquinaria».

17 Es el caso, por ejemplo, de la Mancomunidad de Proaza-Quirós-Teverga y Santo Adriano en el valle de Trubia, la de los Concejos del Oriente o la Mancomunidad Suroccidental de Asturias.

18 Por Ley de su Parlamento 22/1987 de diciembre, se procedería al establecimiento de la división y organización comarcal en esa Comunidad. Ley modificada por la norma de igual rango, 3/1990, de 8 de enero. La Ley 5/1988, de 28 de marzo, crearía, por su parte, las Comarcas del Pla de L'Estany, el Plá d'Urgel y la Alta Ribagiorça.
} 
de dispensa; ejercer competencias municipales por delegación o convenio; establecer y prestar servicios supramunicipales complementarios de los municipales, disponer la conversión de competencias municipales en comarcales y coordinar los servicios municipales entre sí por razones de interés comarcal".

Cabe destacar, sin embargo, la existencia de una importante falta de equivalencia entre el extraordinario protagonismo que la Comarca reviste en los textos normativos catalanes y la realidad de su funcionamiento cotidiano. Como insinuara T. FonT 19 , hace ya cierto tiempo, parece apreciarse una cierta languidez en la actividad de estas Entidades. Las leyes autonómicas que deben atribuirles competencias las ignoran absolutamente en la mayoría de los casos y, en las pocas ocasiones en que las toman en consideración, se limitan a conferirles el simple derecho a participar en órganos colegiados o a intervenir, con funciones de consulta, en procedimientos autonómicos. En definitiva, la creación de la Comarca en Cataluña no se ha visto acompañada de ese paralelo proceso de atribución de competencias del que su propia Ley reguladora hacía depender, en última instancia, su éxito o fracaso. Un hecho al que no es ajeno, sin duda, el de la multiplicidad de instancias llamadas a convivir en un mismo ámbito territorial y gobernadas, además, por fuerzas políticas de muy distinto signo. ¿Puede realmente funcionar una Comarca con verdadero protagonismo y autoridad sobre un espacio en el que, junto a ella, se despliegan los poderes de Municipios, Provincias, Administración autonómica y Estado, sin contar con las ochenta y ocho Mancomunidades existentes, las Entidades Metropolitanas del área barcelonesa y alguna que otra empresa privada de gestión de servicios públicos?

\section{c) La Comarca del Bierzo en la Comunidad de Castilla y León}

«Por las correspondientes Leyes de Cortes de Castilla y León, específicas para cada supuesto, se podrán reconocer Comarcas, mediante la agrupación de Municipios limítrofes, atendiendo al informe previo de los Municipios afectados y a sus características geográficas, económicas, sociales e históricas para la gestión en común de servicios o la colaboración en el ejercicio de sus competencias".

Con base en esta previsión contenida en el artículo 19.3 de su Estatuto, una Ley del Parlamento de Castilla y León, la Ley 1/1991, de 14 de

19 "La Comarca y las estructuras del gobierno local...", ob. cit., págs. 289 y ss. 
marzo, procedió a la creación y regulación de la Comarca del Bierzo, integrada por los Municipios que expresamente determina su artículo primero y de susceptible ampliación a otros limítrofes a través del procedimiento que en ella misma se prevé.

Competencias de diferente origen pueden nutrir el ámbito de actuación propio de esta Comarca, conforme a lo dispuesto en el Capítulo II de la citada Ley. De una parte, aquellas competencias que le atribuya la legislación sectorial en ámbitos, tan variados e importantes, como «la ordenación del territorio y urbanismo; sanidad; servicios sociales; cultura y deporte; salubridad pública y medio ambiente; turismo y tradiciones populares; artesanía; agricultura, ganadería y montes, minería; ferias y mercados comarcales y energía y producción industrial»; de otra, aquellas de procedencia municipal cuando "su realización o prestación resulte imposible o muy difícil para los Municipios y razones de economía y eficacia así lo aconsejen»; por último, las que sean objeto de transferencia o delegación por la Comunidad Autónoma, la Diputación de León o los Municipios que la integran.

En definitiva, y una vez más ésta viene a convertirse en la conclusión obligada, no estamos ante una Ley de la que deriven directamente competencias en favor de la Entidad que crea, sino ante una norma que se limita a fijar cuáles son aquellos sectores de la actividad de los que éstas pueden, en su caso, extraerse, así como las vías o cauces conforme a los cuales ese mecanismo de atribución de competencias puede llevarse a cabo. Una opción de tal tipo deja a la Comarca del Bierzo, como ya había dejado antes a las catalanas y dejará posteriormente a las que puedan crearse en Aragón, ante la acción futura e incierta de unos Parlamentos en cuya concepción territorial lo mismo puede haber espacio para una opción favorable a la consolidación de la Comarca como unidad territorial verdaderamente importante y representativa, que una posición partidaria, en el otro extremo, de dejar reducido su papel a una presencia meramente testimonial. A estas alturas, no puede aventurarse más, al no ser todavía mucho el tiempo transcurrido, aunque todos los indicios apunten hacia la segunda de las direcciones. No se conocen, hasta la fecha, Leyes del Parlamento castellano-leonés que atribuyan a la Comarca del Bierzo competencias verdaderamente importantes; carácter que, por el contrario, sí ostentan la generalidad de las conferidas a la Mancomunidad de Municipios del Bierzo Suroeste -recogida y tratamiento de residuos sólidos, protección y mejora del medio ambiente en general y, en concreto, ríos, montes...; promoción del deporte, turismo y todo tipo de manifestaciones culturales autóctonas, protección de la agricultura y ganadería de la zona...-; una 
Mancomunidad en la que se integran no pocos de los Municipios que conforman la citada Comarca. Su empleo, de otra parte, a los meros efectos de una prestación asociada de servicios municipales no justifica el sostenimiento de una Entidad de este género. A tales fines, los Ayuntamientos cuentan con otras fórmulas de más fácil articulación.

d) La amplia regulación de la Entidad comarcal en la Comunidad de Aragón.

La Ley 10/1993, de 4 de noviembre, del Parlamento de Aragón ha ofrecido en el Derecho español la última regulación específica de la Entidad comarcal. Una norma que, al decir de su propio Preámbulo, aspira a ofrecer «el tipo de organización comarcal que se considera adecuado al conjunto de la realidad aragonesa, sin perjuicio de las especialidades que cada Comarca pueda prever para adaptarlo a sus peculiaridades específicas».

Entidad territorial creada por Ley para la prestación de servicios y la gestión de actividades de ámbito supramunicipal, representando los intereses de su población y territorio constituyen las notas básicas de su definición legal. La Ley de creación se convierte no obstante en ésta, como en tantas otras Comunidades Autónomas, en la pieza normativa básica de cada Entidad. A ella compete, artículo 5, determinar «su denominación, ámbito territorial, capitalidad, composición y funcionamiento de sus órganos de gobierno que serán representativos de los Ayuntamientos que las formen, así como las competencias y recursos económicos propios de las mismas».

El Capítulo III de la norma distingue - como viene, igualmente, siendo usual en normas de este tipo- diferentes clases de competencias comarcales en atención a su procedencia y carácter. Así: a) competencias propias: aquellas «que les sean atribuidas por su Ley de creación y, entre otras, las siguientes: ordenación del territorio y urbanismo; protección del medio ambiente; acción social; cultura; deportes; promoción del turismo; artesanía; ferias y mercados comarcales; protección de los consumidores y usuarios; protección civil y prevención y extinción de incendios; transportes; patrimonio histórico-artístico; servicios de recogida y tratamiento de residuos sólidos y aquellas otras que con posterioridad a la presente Ley o a las de su creación pudieran ser ejercidas en el futuro por las comarcas»; b) competencias transferidas o delegadas por la Comunidad Autónoma, cuando con ello se favorezca la mejor prestación de los servicios co- 
rrespondientes, por la Provincia «en relación con la gestión del Plan Provincial de Obras y Servicios en el ámbito comarcal» y la asistencia y cooperación técnica, jurídica y económica a los Municipios «cuando se refieran a actuaciones de interés comarcal o supramunicipal y cuando su ejercicio resulte difícil para el Municipio y razones de economía y eficacia así lo aconsejen"; c) la gestión, en virtud de convenio, delegación o transferencia, de las actuaciones prioritarias específicas que se fijen en los planes y programas territoriales aprobados en desarrollo de las directrices de ordenación del territorio; d) la cooperación y asistencia a los Municipios en materia jurídico-administrativa, económica y financiera; e) la gestión de servicios autonómicos que por sus características no requieran unidad de gestión ni su ejercicio directo o de servicios municipales cuando ello suponga una mejora en su prestación; y f) la prestación de servicios originariamente mancomunados y que, una vez constituida la Entidad, se transformen en comarcales.

Pocas dudas caben sobre el espíritu comarcalizador que preside todo el texto de la Ley, patente no sólo en este ámbito de las competencias, sino igualmente manifiesto en el conjunto de medidas de fomento a un proceso de comarcalización del territorio aragonés - Capítulo VIII-, en la declaración de Mancomunidades de interés comarcal como fórmula transitoria para la prestación de funciones y servicios hasta su asunción total por la Comarca - artículo 33-y en la creación de los denominados Consejos comarcales como órganos de carácter consultivo y deliberante en aquellas zonas en las que no exista todavía una Entidad local de esta naturaleza -artículo 34-.

Parece claro que esta Ley del Parlamento de Aragón constituye la más completa de las regulaciones hoy existentes sobre la Comarca. Ello no permite, sin embargo, sustentar la existencia de una Entidad de este tipo necesariamente fuerte e importante en aquella Comunidad Autónoma; algo que dependerá de las normas de constitución de cada una de ellas, así como de la actuación posterior del propio Parlamento y de las distintas Administraciones desplegadas en la zona. Los ambiciosos objetivos de la norma de 1993 no tienen por qué verse necesariamente cumplidos. Nada asegura ni garantiza de otra parte, en el caso de que la Comarca llegue efectivamente a instaurarse en todo o en parte del territorio de esta Comunidad, que las distintas normas de creación vayan a respetar ese común marco sentado por la norma general que comento; hipótesis a la que ningún reproche cabría, desde luego, hacer desde el punto de vista jurídico, dada la identidad de rango entre una y otra disposición. 
Sólo el transcurso del tiempo permitirá valorar con exactitud el juego dado por la Comarca aragonesa. Por ahora, no puede sino dejarse constancia de cómo por el territorio aragonés, lo mismo que por el del resto de las Comunidades Autónomas, se extiende una amplia y tupida malla de Mancomunidades municipales - sesenta y una, salvo error u omisión en el cómputo, por mi parte-, muchas de cuyas competencias se desarrollan dentro de aquellos ámbitos materiales -urbanismo, medio ambiente, servicios sociales, culturales, etc... - llamados a constituir el sustrato de las competencias propias de las Comarcas, conforme a su Ley reguladora. Unas Mancomunidades de amplios fines - las del Alto Valle de Aragón, Sobrarbe, la Baja Ribagorza o la de la Calamocha 20_ que hacen dudar, desde estrictas consideraciones de eficacia en el funcionamiento de las Administraciones públicas, sobre su compatibilidad con la Comarca. Sólo la supresión de las Mancomunidades de este porte, ante la aparición de la Comarca, puede hacer, de esta última, una instancia realmente significativa en esta Comunidad Autónoma. Ante los Poderes públicos de Aragón se sitúa, pues, el reto de reestructurar su planta territorial, convirtiendo en Comarcas aquellas Mancomunidades que así lo demanden y manteniendo como tales esas otras que, por la naturaleza de sus competencias, no exijan de esta operación de transformación.

\section{e) La Comarca en otros Derechos autonómicos}

Existe, por último, un bloque de ordenamientos autonómicos en los que la Comarca ha hallado algún tipo de regulación en aquellas normas que, a nivel general, disciplinan el Régimen local. Tal es lo que ocurre, por ejemplo, en la Comunidad Autónoma de Murcia que dedica a esta Entidad el Capítulo I del Título III de la Ley 6/1988, de 25 de agosto, de Régimen local. Cabe destacar de esta norma la profunda contradicción que parece producirse entre su artículo 1, conforme al cual la Comarca resulta ser elemento necesario de la organización territorial de esa Comunidad y el 59 del que se desprende un principio dispositivo en su creación. Si es Entidad básica, conforme a su Estatuto, no parece que quepa otra solución que la de su efectiva implantación. Tal contradicción no debe considerarse, en último término, sino una muestra más de la generalizada ausencia en las Comunidades Autónomas de criterios claros sobre su planta territorial.

20 En el Informe del MAP, reiteradamente citado en este trabajo, puede encontrarse la larga lista de cometidos de esta y otras Mancomunidades similares. 
En otros Derechos autonómicos, por último, la Comarca no ha encontrado acogida. Tal es el caso, por ejemplo, de la Ley 3/1991, de 4 de marzo, de Entidades locales de la Comunidad de Castilla-La Mancha, en cuyo Título Tercero y bajo la rúbrica de "Asociacionismo municipal», se contemplan sólo las Mancomunidades de Municipios y las agrupaciones municipales a efectos del mantenimiento conjunto del personal funcionario con habilitación nacional o de la más reciente Ley 7/1993, del Parlamento de Andalucía sobre Demarcación municipal, en donde la Comarca brilla, igualmente, por su ausencia en la regulación que de las Entidades supramunicipales realiza su Título III.

\section{Conclusiones. La configuración definitiva de la Comarca como Administración territorial. Su difícil articulación}

No obstante la cierta ambigüedad de la regulación legal de esta Entidad en la LBRL, los Estatutos de Autonomía y algunas Leyes autonómicas sobre el Régimen local, la decantación de nuestro Derecho por una Comarca de naturaleza territorial es clara. Ya intuida en el primer escalón de su regulación normativa - la LBRL y los Estatutos de Autonomía-, tal condición se manifiesta con absoluta nitidez en las Leyes específicas sobre esta Entidad promulgadas hasta la fecha. Más concretamente, se hace patente en la generosidad que preside la atribución de competencias a su favor y en la determinación de su ejercicio en régimen de autonomía; en el amplio elenco de potestades administrativas que se les confieren: las propias de los entes territoriales; en la base democrática o representativa de sus órganos de gobierno y administración y, por último, en el principio de reserva de Ley que rige su creación frente al simple pacto asociativo que caracteriza la constitución de una Mancomunidad de Municipios.

Las Comarcas son, en última, instancia, esa "circunscripción territorial propia de la Comunidad Autónoma" a la que se refiere el artículo 152.3 de la Constitución; una Entidad pensada y diseñada para ostentar un protagonismo que trasciende al de mero cauce para la prestación de ciertos servicios ante supuestos de insuficiencia o mera conveniencia municipal. La Comarca -vista desde otra perspectivano es la solución organizativa a las carencias de los Municipios en el ejercicio de algunas de sus competencias, aunque, una vez constituida, pueda y deba desempeñar ese papel, evitando así una posible reduplicación de instancias surpramunicipales. La comarcalización supone, en síntesis, un proceso de descentralización del poder llamado a afec- 
tar, en primer término y antes que a ninguna otra instancia, a las Comunidades Autónomas. Es, en ilustrativas palabras de la Exposición de Motivos de la Ley creadora de la Comarca del Bierzo, «la investidura político-administrativa de las singularidades propias de un espacio» que llegó a tener cierta personalidad administrativa «incluso once años antes de que Javier de Burgos llevase a cabo la división provincial integrando la comarca del Bierzo en la actual provincia de León". El problema de la Comarca no es así, en nuestro Derecho, un problema de cantidad de competencias, sino de cualidad en su ejercicio; la institucionalización del nivel comarcal supone la configuración de una Entidad para la gestión en régimen de autonomía de los intereses propios de las colectividades que les sirven de sustrato, de donde deriva el necesario carácter democrático de sus órganos de gobierno y administración.

En esta concepción de la Comarca radica su importancia, al tiempo que su dificultad. En un extremo penden de la acción de un legislador que, hasta la fecha, no se ha caracterizado, precisamente, por su grado de generosidad a la hora de atribuir competencias a esta Entidad; en el otro, de una Administración municipal que encuentra en el propio ordenamiento jurídico instrumentos de más fácil articulación para la prestación conjunta de sus propios servicios: una Mancomunidad, un Consorcio, una Entidad de Derecho privado o, incluso, un simple convenio. En suma, la realidad se halla muy lejos de ese modelo comarcal que, como rescate quizá de una inercia histórica rota en el pasado más reciente, algunas Comunidades Autónomas intentan plasmar. No sé, ante todo ello, si resultaría una exageración, por mi parte, afirmar que nos encontramos ante una Entidad que no termina de encajar en una organización territorial, ya de por sí compleja, como es la diseñada por la Constitución de 1978. El papel que la Comarca haya de ocupar, nítido en el plano de las ideas y con plasmación en algunos textos normativos, se encuentra absolutamente desvirtuado en la realidad. El estudio de la figura de la Mancomunidad de Municipios vendrá, desde su propia perspectiva, a abundar en esta afirmación.

\section{LAS MANCOMUNIDADES DE MUNICIPIOS, LA FÓRMULA NATURAL DE PRESTACIÓN DE SERVICIOS MUNICIPALES EN NUESTRO DERECHO}

La distinción entre Derecho estatal y Derecho autonómico puede, al igual que antes, servirnos de hilo conductor en el examen de esta Entidad. 


\section{La regulación de las Mancomunidades en la Ley de Régimen Local de 1985. Sus rasgos distintivos}

«1. Se reconoce a los Municipios el derecho a asociarse con otros en Mancomunidades para la ejecución en común de obras y servicios determinados de su competencia.

2. Las Mancomunidades tienen personalidad y capacidad jurídica para el cumplimiento de sus fines específicos y se rigen por sus Estatutos propios. Los Estatutos han de regular el ámbito territorial de la Entidad, su objeto y competencia, órganos de gobierno y recursos, plazo de duración y cuantos otros extremos sean necesarios para su funcionamiento.

En todo caso, los órganos de gobierno serán representativos de los Ayuntamientos mancomunados.

3. El procedimiento de aprobación de los Estatutos de las Mancomunidades se determinará por la legislación de las Comunidades Autónomas y se ajustará, en todo caso, a las siguientes reglas:

a) La elaboración corresponderá a los Concejales de la totalidad de los Municipios promotores de la Mancomunidad, constituidos en Asamblea.

b) La Diputación o Diputaciones Provinciales interesadas emitirán informe sobre el proyecto de Estatutos.

c) Los Plenos de todos los Ayuntamientos aprueban los Estatutos.

4. Se seguirá un procedimiento similar para la modificación o supresión de Mancomunidades».

Dos notas definen, pues, a las Mancomunidades municipales en el artículo 44 de la Norma estatal del Régimen local: su origen en la voluntad municipal y su adscripción a la ejecución de una obra o la prestación de un servicio de los Municipios que las crean. De ellas interesa, a los fines de este estudio, su objeto, cuyo análisis nos permitirá alcanzar el lugar que esta institución ocupa dentro del más amplio mundo de las Entidades supramunicipales.

En este plano de delimitación del objeto de la Mancomunidad, ha de indicarse, en primer término que las nociones de "obras" y "servicios", de gran tradición, por otra parte, en nuestro Derecho, deben ser entendidas en un sentido amplio, como comprensivas, en clásica expresión de E. GARCIA DE ENTERRf́, del "giro o tráfico administrativo» 21. Desde esta

21 E. GARCIA DE ENTERRIA $y$ T.R. FERNÁNDEZ: Curso de Derecho Administrativo, Vol. I (Ed. Civitas, 1993, pág. 54). 
perspectiva, puede considerarse que los Municipios están legitimados para transferir a una Mancomunidad el ejercicio de cualquier competencia de la que dispongan en aplicación de la LBRL y demás normas en la materia 22 y sustentar, por consecuencia, la licitud, por ejemplo, del sostenimiento en común de una banda de música ${ }^{23}$, la construcción de viviendas de protección oficial 24 o la recogida de perros callejeros 25 como posibles objetos de una Mancomunidad municipal.

La exigencia de determinación en la obra o servicio transferido completa la delimitación del objeto de la Mancomunidad en la LBRL. Pocas dudas ha de plantear un requisito bajo el que no parece que se encubra algo diferente del deber de delimitación precisa y exacta de la competencia o competencias de prestación mancomunada. No es condición que imposibilite, en cambio, que a la Mancomunidad se atribuya más de un cometido. De hecho, si alguna nota caracteriza a esta Entidad en su configuración actual, es, precisamente, la de la amplitud de su objeto. Más adelante me detendré en esta idea.

La particular idoneidad de esta figura en el ejercicio de aquellas competencias en las que la escala municipal se ha visto superada, se manifiesta, además, en el empleo que no pocas normas sectoriales hacen de ella en orden al ejercicio de algunas de las funciones que atribu-

\begin{abstract}
22 En tal sentido, X. MURO I BAS ( El régimen competencial de las Mancomunidades municipales en la Ley 7/1985, de 2 de abril». Revista Vasca de Administración Pública, n. ${ }^{\circ} 18$, 1987, págs. 133 y ss.).

Quizá pueda resultar ilustrativa la lista de objetos de las Mancomunidades existentes ofrecida por el MAP. Aparte de la existencia de Mancomunidades en relación con todos y cada uno de los servicios municipales establecidos en al artículo 26 de la LBRL, existen Entidades de este tipo que, por orden decreciente en número tienen como fines los siguientes: educación y cultura, turismo, servicios técnicos, urbanismo, tratamiento de aguas residuales, sanidad, fomento agrícola y forestal, mantenimiento general de servicios, recaudación, informatización y mecanización administrativa, parque de maquinaria, fomento industrial, obras públicas, máquinas quitanieves, información al consumidor, fomento de la vivienda, lucha contra el paro, recogida de perros vagabundos, euskaldunización, radio y/o televisión, desratización, limpieza de playas, mantenimiento de parques y jardines, pompas fúnebres, electrificación, servicio de lectura de contadores de agua, parque móvil, academia de personal municipal, teléfonos, servicio de fontanería, caja de cooperación, servicio de taxis, feria y mercados (Las Mancomunidades Intermunicipales en el Régimen local español, ob. cit.).
\end{abstract}

${ }^{23}$ Mancomunidad del Noreste de Gran Canaria.

${ }^{24}$ Mancomunidad de Municipios de La Venera en la Comunidad de Cantabria.

25 Mancomunidad de Municipios de la Bahía de Cádiz. 
yen a los Municipios. Así ocurre en el ámbito del Derecho urbanístico 26, la regulación de los transportes 27 , la recogida y tratamiento de desechos y residuos sólidos urbanos ${ }^{28}$, el abastecimiento de agua a poblaciones ${ }^{29}$, la protección civil ${ }^{30}$ o los montes ${ }^{31}$.

La Mancomunidad que la LBRL diseña constituye, en suma, una Entidad local nacida de un acto de autodisposición de sus propias competencias por parte de los Municipios implicados, en cuya virtud otorgan al nuevo ente la ejecución de una obra o la prestación de un servicio ínsito en su propia esfera, fijando al mismo tiempo, y a través de sus Estatutos - norma básica de la Entidad-, el régimen jurídico y económico que haya de regirlas. Al margen de ella quedan, en consecuencia, los amplios procesos de reajuste en la distribución del poder que han de ponerse en marcha a resultas de la creación de una Comarca o, incluso, de un Área metropolitana; de ahí la mayor simplicidad de su procedimiento de constitución que no requiere, como en el caso de las Entidades anteriores, de una Ley para su creación, pero de ahí, igualmente y a cambio, una exigencia básica en orden a su creación: el acuerdo unánime de los Municipios afectados.

\section{El desarrollo e implantación de las Mancomunidades en el ordenamiento autonómico}

Son mayoritarios los Estatutos de Autonomía que reconocen las agrupaciones municipales de carácter funcional y fines específicos 32; otros no las mencionan expresamente, si bien la atribución de compe-

26 Vid. el Texto Refundido de la Ley del Suelo.

27 Ley 16/1987, de 20 de julio de Ordenación de los Transportes terrestres. En parecidos términos se manifiesta el RD 236/1983, de 9 de febrero.

28 Ley 42/1975, de 19 de noviembre.

${ }^{29}$ Reglamento del Dominio Público Hidráulico.

30 Orden Ministerial de 16 de marzo de 1990 sobre subvenciones a las Corporaciones Locales para la creación de infraestructuras derivadas de los Planes de Emergencia nuclear.

31 Ley 55/1980, de Montes vecinales en mano común.

32 En tal sentido, artículo 5.2 del Estatuto de Cataluña; 40.2 del gallego; 36.2 de la Norma básica de Cantabria; 9.1 del Estatuto de La Rioja; 3.2 del de Murcia; 29.2 b) del Estatuto de Castilla-La Mancha; 8 del de la Comunidad extremeña y 3.2 de la norma de igual rango de la Comunidad de Madrid. 
tencias a sus Parlamentos sobre el Régimen local abren la puerta a una regulación autonómica de estas Entidades. Es ésta, por lo demás, la Administración supramunicipal con mayor implantación, dada la relativa facilidad de su procedimiento de constitución; su menor problematicidad desde el punto de vista jurídico y las importantes necesidades a las que, por lo común, vienen a dar respuesta ${ }^{33}$.

Son éstas, sin duda, las razones que explican su profusa acogida en la Legislación sobre Régimen local. Así, la Ley catalana 8/1987, de 15 de abril, Municipal y de Régimen local las regula en su Título X, definiéndolas, en el artículo 113, como asociaciones de Municipios "para la ejecución en común de alguna o algunas obras y para la gestión de servicios de su competencian; la Ley aragonesa 6/1987, de igual fecha, 15 de abril, declara en su artículo primero que la Mancomunidad es una asociación de Municipios para «la ejecución en común de obras y servicios determinados de su competencia y la intervención coordinada en aquellos asuntos que promuevan el desarrollo económico y social de su ámbito". Por su parte, la Ley murciana de Régimen local, Ley 6/1988, de 25 de agosto, afirma su carácter de Entidad local con personalidad y capacidad jurídica para el cumplimiento de sus fines, proclamando, artículo 63, la especialidad y concreción de su objeto. Unas claves que subyacen, igualmente, en la regulación que de las Mancomunidades establece la Ley 6/1990, de 2 de julio, de Administración local de Navarra; la Ley 14/1990, de 26 de julio de Régimen jurídico de las Administraciones Públicas canarias; la Ley de Entidades Locales de Castilla-La Mancha de 4 de marzo de

\footnotetext{
33 Conforme a los datos ofrecidos por el propio Ministerio para las Administraciones Públicas y actualizados con fecha 28 de febrero de 1994, puede afirmarse que el número aproximado de Mancomunidades en España es de 900, entre las que hay que distinguir aquellas que tienen por fines estatutarios la prestación de servicios municipales de su competencia (763) y aquellas otras más antiguas (normalmente anteriores al Estatuto Municipal de 1924) cuyo objeto es la administración de un patrimonio común, generalmente forestal, así como en casos singulares, aprovechamiento de aguas, caza, o fincas agrícolas-ganaderas.

En el ámbito de las primeras, que son obviamente las que nos interesan, puede afirmarse que de los 8.092 Municipios existentes en España, 4.842 están mancomunados; que es Castilla y León con 164 Entidades de esta naturaleza la que se lleva la palma por Comunidades Autónomas y que la recogida de residuos y el tratamiento y eliminación de residuos sólidos constituyen cuantitativamente el objeto más propio y característico de esta Entidad. 415 Mancomunidades tienen por fin la recogida de residuos y 399 el tratamiento de residuos sólidos.

Destacar, desde otro ángulo, el creciente y llamativo aumento en el número de Mancomunidades desde la promulgación de la Constitución y a partir, sobre todo, de la LBRL. En este sentido se ha pasado de las 165 existentes en 1978, a las 287 de 1985 y, de ahí, a las 763 del año 1994 (Las Mancomunidades Intermunicipales en el Régimen local español..., ob. cit., págs. 30 y ss.).
} 
1991; la Ley de Mancomunidades de las Islas Baleares, Ley 5/1991, de 27 de febrero; la Ley 7/1993, de Demarcación municipal en Andalucía o la Ley de Régimen Local de La Rioja de septiembre de ese mismo año.

Composición exclusivamente municipal, voluntariedad en su constitución y ejecución de obras o prestación de servicios municipales como objeto propio ${ }^{34}$, puede afirmarse, en consecuencia, que constituyen para el Derecho autonómico, de la misma forma que para la LBRL, los elementos vertebradores de esta Entidad, siendo estas características las que la convierten en la fórmula por excelencia de prestación asociada de servicios municipales.

Esta amplia disponibilidad de los Municipios sobre la Mancomunidad se manifiesta no sólo en la determinación de su objeto, sino también en la fijación por ellos mismos, y a través de sus Estatutos, de la propia organización y régimen de funcionamiento del ente, dentro del respeto a los límites establecidos por la LBRL y a lo dispuesto, en su desarrollo, por las normas autonómicas. Es la voluntad, en definitiva, de los Ayuntamientos, como afirma la Exposición de Motivos de la Ley de Mancomunidades de las Islas Baleares, la que dirige y gobierna estas Entidades, limitándose el papel de la Comunidad Autónoma «a asistirlos y colaborar con ellos en su creación y organización».

\section{Valoración. La Mancomunidad de nuestro tiempo. ¿Una pérdida del sentido de la figura conforme a su regulación en la LBRL?}

La creciente expansión de su objeto, marca, sin duda alguna, el actual régimen de las Mancomunidades de Municipios en España y las sitúa, en no pocas ocasiones, en el extremo mismo de la legalidad, conforme a su configuración en la LBRL. Aunque la definición jurídica de las Mancomunidades no ha cambiado en exceso con el transcurso histórico ${ }^{35}$, durante un no corto espacio de tiempo, estas Entidades solían

\footnotetext{
34 Tales características han hecho decantarse abiertamente a la doctrina por la proclamación de su condición de ente institucional. En tal sentido, y entre otros, R. MARTIN MATEO (Entes locales complejos..., Ed. Trivium págs. 45 y ss.); F. Lliset BorRell (Manual de Derecho local..., ob. cit., págs. 226 y 27); J. L. RIVERo ISERN (Manual de Derecho local.., ob. cit., págs. 172-73); F. SOSA WAGNER («Mancomunidades y otras formas asociativas», Tratado de Derecho Municipal I, ob. cit., págs.1.043 y ss.) y X. MURo I BaS («El régimen competencial de las Mancomunidades en la Ley 7/1985, de 2 de abril...», ob. cit., págs. 124 y 5).
}

35 Sobre el origen y evolución histórica de esta figura, me remito a F. Sosa WAGNER («Mancomunidades y otras formas asociativas», Tratado de Derecho municipal..., ob. cit., 
constituirse para la prestación de un servicio concreto, siendo hoy, por el contrario, cada vez más frecuente la existencia de Mancomunidades que asumen un alto y variado cúmulo de funciones. Cuando lo que está en juego es la gestión de un servicio específico, otras fórmulas parecen resultar más idóneas que ellas: las formas societarias propias del Derecho mercantil, los consorcios e, incluso, los convenios formulados al amparo del artículo 57 de la LBRL.

Esta Mancomunidad de amplios fines se manifiesta, tomando como exponente, a título ilustrativo, la Comunidad Autónoma de Andalucía -páginas atrás las ejemplificábamos en el territorio aragonés-, en Mancomunidades como la de Cádiz o la cordobesa del Alto Guadalquivir. Así, la primera posee competencias tan diversas e importantes como las de: "alcantarillado, cementerio, infraestructura viaria y comunicaciones intermunicipales, medios de telecomunicación social, limpieza viaria, limpieza de playas, participación en la gestión de parques naturales, promoción y gestión de suelo y viviendas, promoción turística, protección del medio ambiente, recogida y tratamiento de residuos, servicio de recogida de perros, transporte público de viajeros, tratamiento de aguas residuales y vertederos de escombros»; la segunda, las de «mejoras socioeconómicas, ordenación del territorio y urbanismo, obras públicas, medio ambiente, basuras, abastecimiento de agua potable, prevención y extinción de incendios y protección civil, abastecimientos, transportes y comunicaciones, sanidad, turismo y ocio, cultura, deportes y enseñanza, recaudación de contribuciones y servicios sociales". Las Mancomunidades del Campo de Gibraltar, el Mencal, Costa Tropical o la Axarquía se sitúan en esta misma línea ${ }^{36}$.

págs. 1.041 y ss.), así como a los trabajos de T. Quintana LOPEz (Las Mancomunidades en nuestro Derecho Local, Ed. MAP 1990, págs. 15 y ss.) y FERNÁNDEZ DE GATTA ( El régimen normativo de las Mancomunidades Municipales". Revista Vasca de Administración Pública n. ${ }^{\circ} 37,1993$, págs. 85 y ss.).

36 Junto a éstas, siguen existiendo, no obstante, Mancomunidades para fines específicos. Tomando, de nuevo, como punto de referencia la realidad andaluza, puede hacerse mención, a título puramente ilustrativo, a diferentes Mancomunidades presididas por un principio de especialidad en sus fines, ya sea la prestación de un servicio municipal mínimo, como el de abastecimiento de agua potable -Mancomunidad del rio Dilar o del Temple, por ejemplo- o el de recogida, tratamiento y eliminación de residuos - Mancomunidad de los Alcores, de la zona norte de Antequera, del Andévalo o de la Cuenca minera - o un objetivo relacionado, por lo común, con las condiciones socioeconómicas de la zona - tal ocurre, por ejemplo, con la Mancomunidad de la zona subbética cordobesa para la promoción y desarrollo del turismo o con la de la Comarca del Mármol "Blanco Macael» para la «explotación conjunta de los aprovecha- 
No sólo la realidad aboga claramente por este modelo de Mancomunidad de amplios fines; puede entenderse, además, que el Derecho de nuestros días está pensando en una Entidad de este corte. Dos preceptos, de diferentes normas, así lo evidencian. De una parte, el artículo 35.2 del Texto Refundido de Régimen Local que, al igual que harán posteriormente algunas normas de las Comunidades Autónomas 37, impide una posible atribución de todas las competencias municipales a una Mancomunidad 38; de otra, el 36 del Reglamento de Población y Demarcación que, al contemplar la hipótesis de que un Municipio se integre en una Mancomunidad ya existente, prevé expresamente que tal adhesión se produzca respecto de «una, varias o todas las finalidades de la Mancomunidad...".

También el propio Ministerio para las Administraciones Públicas se ha hecho eco expreso de la recepción de este fenómeno, al distinguir entre "Mancomunidades tradicionales", que generalmente lo son para un fin concreto, y "Mancomunidades evolucionadas" que, más bien, constituyen «un programa de futuras realizaciones y en el que se pone de manifiesto una voluntad política de declinar competencias municipales en favor de ir configurando a través de la asociación voluntaria, un nuevo ente local supramunicipal que asuma la prestación de los servicios municipales (no sólo los mínimos u obligatorios)... Se busca en ese modelo de Mancomunidad lo que en algunos proyectos legislativos se denominó Mancomunidad Comarcal... y en alguna Legislación autonómica (Aragón, La Rioja) se denomina Mancomunidades de interés comarcal o de interés preferente». "Igualmente se observa en algunas

mientos mineros «Blanco Macael» y el fomento, industrialización y comercialización del mármol de la zona.

Lo expuesto para esta Comunidad Autónoma vale, de igual forma, para el resto de ellas. Al informe publicado recientemente por el MAP, y citado aquí de forma reiterada, me remito. La generalidad de las Mancomunidades de Municipios, la gran mayoría de ellas creadas tras la puesta en marcha del proceso de reforma local que se inicia en 1978, y en particular a partir del año 1985, sirven a una pluralidad de fines muy diversos, entre los que se encuentran no sólo servicios municipales mínimos del artículo 26, sino también otros cometidos de mayor calado, generalmente relacionados con el desarrollo y promoción industrial, en diferentes manifestaciones, de los Municipios que las integran.

37 Artículos 42 de la Ley de Entidades locales de Castilla-La Mancha, 63 de la Ley de Murcia, 47.3 de la Ley de Régimen Local de Navarra; 61 de la Ley 3/1993, de 22 de septiembre, de Régimen local de La Rioja y 23 de la Ley 7/1993, de Demarcación Municipal de Andalucía.

38 Una solución de tal tipo no vendría a suponer, además, sino una vía encubierta de fusiones municipales al margen, por consecuencia, de los cauces legalmente previstos al efecto. En tal sentido, T. QUINTANA LOPEZ, "Las organizaciones supramunicipales en España: Las Mancomunidades», REALA n. ${ }^{\circ} 254 / 1992$, pág. 314.). 
Comunidades Autónomas (Aragón) —continúa el Informe más adelante- la aparición de Mancomunidades con el fin de «rodar», la futura comarcalización del territorio de la Comunidad respectiva...» 39.

Nada hay que objetar, pues, a esta Mancomunidad flexible y abierta al desempeño de un conjunto amplio y heterogéneo de cometidos municipales, favorecida, importa reseñarlo, por la circunstancia histórica de la uniformidad en las fuerzas políticas gobernantes en la generalidad de los Municipios durante los últimos años; si bien conviene llamar la atención sobre lo que pudiera calificarse de un cierto estiramiento legal de la figura conforme a los rasgos que la definen en la LBRL. Y ello, al conferírseles, en algunos supuestos, competencias que van más allá de esa ejecución de obras o prestación de servicios, de origen, en todo caso, municipal, que enmarcan a la figura en la legislación estatal. Un hecho que no sólo se manifiesta en Mancomunidades como las de la Baja Ribagorza, entre cuyos fines estatutarios se encuentran "la coordinación y partícipación en los medios sanitarios comarcales" y "la mejora de los medios de comunicación (TV, radio, prensa escrita) o en la Intermunicipal del Sureste de Gran Canaria para, entre otros cometidos, «la coordinación y, en su caso, la ejecución de programas, proyectos, estudios y actuaciones tendentes a satisfacer las necesidades sociales, culturales, sanitarias, recreativas y de servicios»; sino también, y es lo más importante, en las propias normas jurídicas reguladoras de esta Entidad en algunas Comunidades Autónomas. Tal es lo que ocurre en la Ley de Mancomunidades de Aragón, cuyo artículo primero les atribuye, además de los fines determinados en el artículo 44 de la norma estatal, "la intervención coordinada en aquellos asuntos que promuevan el desarrollo económico y social de su ámbito" y en la de las Islas Baleares en las que se contempla, artículo 19, entre los cometidos propios de estas Entidades, "la planificación y desarrollo industrial y agrícola para la mejora de las condiciones de vida en su ámbito territorial».

No se cuestiona la posible bondad de tales previsiones. Pero, ¿no estamos por esta vía asistiendo a una auténtica distorsión de la Mancomunidad, en detrimento de las Comarcas?; ¿no se estaría utilizando el más fácil expediente de creación de Mancomunidades para dar respuesta a problemas que tienen en otras Entidades su cauce más idóneo de satisfacción? Previsiones del tipo de las ejemplificadas en las Mancomunidades de la Alta Ribagorza o del Sureste de Gran Canaria ¿no

39 (Las Mancomunidades Intermunicipales en el Régimen local español..., ob. cit., págs. 19 y 20). 
suponen, en definitiva, una extralimitación en el papel asignado por la LBRL a esta Entidad?; ¿no se hallará en esta vis expansiva de la figura de la Mancomunidad una de las causas más importantes del fracaso de la Comarca en nuestro Derecho? En todo caso, las dudas, en este terreno no han trascendido del ámbito de la discusión teórica, sin que tampoco quepa afirmar que las críticas vertidas hayan sido muchas, ni muy fuertes; previsiones de esta naturaleza han pasado más bien desapercibidas.

La Mancomunidad constituye, en suma, el cauce expresamente previsto en nuestro Derecho para la ejecución de obras o la prestación de servicios ante supuestos de insuficiencia municipal o razones de mera oportunidad o conveniencia 40; lo que no impide que, constituida por otros fundamentos y razones, una Comarca o un Ärea metropolitana, estas Entidades jueguen ese papel que, en principio, el Derecho confiere a la Administración que, ahora, estudio. Lo que no cabría, en ningún caso, es la solución inversa: una Mancomunidad constituida en sucedá-

40 Esta consideración de la importancia de las Mancomunidades a tales fines se hace manifiesta en el conjunto de medidas de fomento que las normas autonómicas contemplan. Así: artículo 9 de la Ley de Aragón; 17 y siguientes de la Ley de las Islas Baleares; diversos preceptos de las Leyes de Régimen Local de Murcia y La Rioja; Ley foral 6/1990, de 2 de julio, de la Administración local de Navarra, (artículos 53 y 62); Ley 3/1991, de 14 de marzo, de Entidades locales de Castilla-La Mancha (artículos 39 y ss.); los Decretos de la Comunidad de Castilla y León 110/1984, de 27 de septiembre, modificado por la norma de igual rango de 21 de diciembre del mismo año, para el fomento de las Mancomunidades y el 36/1988, de 25 de febrero, modificado por el 57/1990, por el que se regula la gestión del Fondo de Cooperación Local de la Comunidad Autónoma (artículos 27 a 31); el Decreto 68/1984, de 15 de diciembre, sobre ayudas a la constitución y funcionamiento de Mancomunidades municipales; el Decreto $9 / 1989$, de 9 de mayo, de Extremadura para la concesión de subvenciones y ayudas para el fomento de Mancomunidades de Municipios.

Por su parte, el RD 665/1990, de 25 de mayo, regula la cooperación económica del Estado a las inversiones de las Entidades locales que tengan por objeto prioritario la financiación de las inversiones necesarias para la efectiva prestación de los servicios obligatorios determinados en el artículo 26 de la Ley básica, aunque los planes también puedan incluir otras obras y servicios que sean objeto de competencia municipal de acuerdo con el artículo 25... Unas ayudas de las que podrán ser beneficiarias las Entidades locales comprendidas en el artículo 3.2 (las Mancomunidades, por tanto). Es más, el artículo 9 de la citada norma prevé que la subvención estatal a los planes provinciales de cooperación a las obras, que normalmente será del 35 por ciento respecto de los servicios y obras del artículo 26 de la LBRL, podrá alcanzar hasta el 45 por ciento ucuando las citadas obras y servicios sean propuestas por Mancomunidades, otras Entidades locales de carácter supramunicipal o mediante fórmulas asociativas entre Entidades locales, que supongan la ejecución de las citadas obras o servicios en beneficio de varios municipios».

Por su parte, las Mancomunidades pueden ser también receptoras de los diferentes tipos de ayudas provenientes de la Comunidad Económica Europea (me remito al respecto al Informe del MAP sobre Mancomunidades... cit., págs. 101 a 103). 
neo de una Comarca, aunque tampoco pueda ni deba desdeñarse el importante papel que puede desplegar como primer paso en la integración municipal de cara a un futuro proceso comarcalizador. A la LBRL no le es, por consiguiente, indiferente el uso que de las Entidades surpramunicipales que diseña se haga. Cada una de ellas está pensada para hipótesis diferentes y las reglas del juego han de respetarse.

\section{LAS ÁREAS METROPOLITANAS, LA POSIBILIDAD DE MODELOS ALTERNATIVOS}

\section{La Ley Básica de Régimen Local y su profunda indefinición en relación con las Arreas metropolitanas}

«1. Las Comunidades Autónomas, previa audiencia de la Administración del Estado y de los Ayuntamientos y Diputaciones afectados, podrán crear, modificar y suprimir, mediante Ley, Áreas Metropolitanas, de acuerdo con lo dispuesto en sus respectivos Estatutos.

2. Las Áreas Metropolitanas son Entidades locales integradas por los Municipios de grandes aglomeraciones urbanas entre cuyos núcleos de población existan vinculaciones económicas y sociales que hagan necesaria la planificación conjunta y la coordinación de determinados servicios y obras.

3. La legislación de la Comunidad Autónoma determinará los órganos de gobierno y administración, en los que estarán representados todos los Municipios integrados en el área; el régimen económico y de funcionamiento, que garantizará la participación de todos los Municipios en la toma de decisiones y una justa distribución de las cargas entre ellos; así como los servicios y obras de prestación o realización metropolitana y el procedimiento para su ejecución.»

Si Comarcas y Mancomunidades de Municipios constituyen, ya hoy, Entidades cuyos rasgos parecen definitivamente perfilados, no puede afirmarse lo mismo en relación con las Áreas Metropolitanas, cuya indefinición en la LBRL ha servido de sustento a Entidades de muy diversa naturaleza ${ }^{41}$.

\footnotetext{
41 Un estudio más completo de esta Entidad puede encontrarse en mi trabajo Las Áreas metropolitanas (Ed. Civitas-Instituto García Oviedo, 1993).
} 
La indeterminación de la norma básica de Régimen local es aquí, en efecto, absoluta ${ }^{42}$. «Las Áreas metropolitanas son, artículo 43, Entidades locales integradas por los Municipios de grandes aglomeraciones urbanas entre cuyos núcleos de población existan vinculaciones económicas y sociales que hagan necesaria la planificación conjunta y la coordinación de determinados servicios y obras». En la definición legal ha primado así más la preocupación por delimitar las características del espacio que sirve de sustrato a una Entidad de este género ${ }^{43}$, que el interés por la caracterización concreta de esta fórmula de organización administrativa supramunicipal. Sus rasgos distintivos ni se explicitan, como ocurre con las Mancomunidades de Municipios, ni se intuyen con tanta claridad, como acontece con la Comarca. La LBRL no diseña un modelo definido de Administración

42 Indeterminación de la que constituye su mejor prueba la diversidad de opiniones que con base en ese precepto y en torno a su naturaleza jurídica se han sustentado. J. R. PARADA VAZQuEz defiende su carácter territorial (Derecho administrativo. Organización y empleo público, Ed. Marcial Pons 1986, pág. 93), al igual que J. L. IbarRa Robles (Las Áreas metropolitanas en el modelo autonómico. Onati 1982, pág. 183). Una afirmación que va a cuestionar, sin embargo, R. MARTIN MATEO porque «aunque la ley podría haber escogido la opción territorial, no lo hizo, y por otra parte no hay más que unas Áreas metropolitanas, las que recoge el artículo 42, si bien pueden arbitrarse soluciones especificas para fines equiparables recurriendo a formulas de otro tipo: mancomunidades, agrupaciones y comarcas, y también consorcios». («Las Áreas metropolitanas». Tratado de Derecho municipal..., ob. cit., pág. 856). En el mismo sentido se manifiestan M. BASsols CoMA ( de las Âreas metropolitanas». El espacio metropolitano, TAL, 30, 1989, pág. 68), P. GARCiA ESCUDERO Y B. PENDÁs GaRCta (El nuevo Régimen local español. Estudio sistemático de la Ley 7/1985 de 2 de abril reguladora de las bases de Régimen local, ob. cit., pág. 259) y F. SoSA WAGNER («Los principios del nuevo Régimen local». Tratado de Derecho municipal..., ob. cit., págs. 125 y 6).

No han faltado, tampoco, posturas eclécticas como las sustentadas por F. LLISET BoRRELL quien entiende que las Áreas metropolitanas "pueden ser en nuestro Derecho, Entidades territoriales -auténticas estructuras de convivencia de segundo nivel-y Entidades no territoriales para fines específicos» (Manual de Derecho local..., ob. cit., pág. 203), A. BAYONA I ROCAMORA ("La nueva ordenación del área metropolitana de Barcelona». El espacio metropolitano..., ob. cit., págs. 138 y 9) y A. FANLO LORAS («Las prerrogativas locales». Tratado de Derecho municipal..., ob. cit., pág. 506).

43 Debe rechazarse, no obstante, la idea de que el concepto de Área metropolitana sea pacífico; en su conceptuación se manejan, por el contrario, criterios o principios de muy diversa naturaleza. A nuestros efectos podemos quedarnos con una definición del Área metropolitana en cuanto fórmula de gobierno y administración de unos espacios caracterizados por una fuerte concentración poblacional en un espacio en el que coexisten varios términos municipales. Sobre el tema pueden consultarse las observaciones realizadas por R. Martin Mateo y J. Allende Landa (El Área metropolitana de Alicante. Un reto de futuro. Ed. Universidad y Ayuntamiento de Alicante, 1986, págs. 21 y ss) y J. L. IBarRA ROBLES «Problemática jurídica actual de las Áreas metropolitanas en España». El espacio metropolitano..., ob. cit., págs. 38 y 9). 
metropolitana; se limita a fijar las formas o técnicas de actuación de esta Administración y alguna que otra regla en materia de organización y procedimiento, remitiendo tanto sus competencias, como su estructura administrativa concreta a lo que se disponga en la Ley de creación de cada Área. Y es que en contra de lo que, en apariencia, el artículo 43 de la LBRL pudiera dar a entender - «las Áreas metropolitanas son "Entidades integradas por los Municipios de grandes aglomeraciones urbanas entre cuyos núcleos de población existan vinculaciones económicas y sociales que hagan necesaria la planificación conjunta y la coordinación de determinados servicios y obras" "- en su marco no sólo cabe un modelo de Administración metropolitana de índole esencialmente coordinadora de competencias que permanecen en manos de otras instancias. Junto a cometidos de esta naturale$\mathrm{za}$, tales Entidades pueden convertirse también en cauce idóneo para la prestación de servicios municipales en el área, así como la instancia receptora de competencias autonómicas que encuentren en la escala metropolitana una unidad de prestación más satisfactoria. Las Entidades metropolitanas no tienen por qué delinearse solamente a partir de cometidos municipales; pueden nutrirse, igualmente, de poderes procedentes de otras instancias; un hecho avalado por la propia exigencia de Ley para su constitución. Aquí, como en la Comarca, puede afirmarse que para el ejercicio en común de una obra o la prestación de un servicio determinado no hace falta acudir a mecanismos tan complejos cuando el propio ordenamiento jurídico ofrece fórmulas de más fácil articulación.

Las Áreas de Barcelona y Valencia, absolutamente divergentes entre sí, constituyen la mejor prueba de la amplia flexibilidad de la LBRL en relación con esta Entidad.

\section{La diversidad del Derecho autonómico sobre Áreas metropolitanas}

Ni son muchos, ni tampoco explícitos, los Estatutos de Autonomía que contemplan expresamente a las Áreas metropolitanas. Tan sólo lo hacen los de las Comunidades de Cataluña 44, Principado de Asturias 45;

\footnotetext{
${ }^{44}$ La previsión de Áreas metropolitanas se halla en el artículo 5.2 "... podrán crearse agrupaciones basadas en hechos urbanisticos y metropolitanos...".

45 Artículo 6.3: «Podrán crearse Áreas metropolitanas».
} 
Murcia 46 y Valencia ${ }^{47}$; si bien la general previsión estatutaria que ampara agrupaciones de Municipios, diferentes de la Provincia, otorga cobertura suficiente a la creación de Entidades de este tipo en aquellas otras Comunidades Autónomas que no las han previsto expresamente.

La opción de la LBRL por un modelo de gobierno metropolitano sumamente abierto ha servido ya de cobertura -como afirmaba anteriormente- a dos modelos de vertebración de los espacios metropolitanos muy distintos entre sí: los representados por las Áreas de Valencia y Barcelona. El primero, en su regulación legal, al menos, parece asemejarse más a los esquemas propios de los entes territoriales, en tanto que el segundo se asienta en Administraciones de clara naturaleza institucional. Unas diferencias que no han de considerarse, en último término, sino el reflejo de la distinta concepción que de su propia planta territorial tienen las Comunidades Autónomas en las que dichas Áreas se integran, trasunto, a su vez y en buena medida, del diferente signo de las formaciones políticas que las gobiernan.

Expongamos brevemente los rasgos más destacados de cada uno de esos modelos.

\section{A. La opción cuasi territorial del Área metropolitana de La Huerta}

Fue la Comunidad de Valencia la primera en adaptar su arcaico régimen especial, el representado por la "Corporación administrativa Gran Valencia" 48, a los nuevos postulados constitucionales. Lo hizo mediante la creación, por ley de su Parlamento de 31 de diciembre de 1986, del Consell Metropolitá de la L'Horta; una Entidad local determinada por «la agrupación de Municipios, con personalidad jurídica propia y plena capacidad para el cumplimiento de sus fines». Ya el propio Preámbulo de la Ley advierte sobre su intención de configurar una Entidad de amplios objetivos, «el establecimiento de unas nuevas coorde-

\footnotetext{
46 Artículo 3.2: «Podrán crearse Areas metropolitanas para la coordinación y gestión de servicios públicos...».

47 Artículo 46.3: "Las áreas metropolitanas... serán reguladas por Ley de las Cortes valencianas, que deberá ser aprobada en las mismas condiciones que en el apartado anterior».

48 Esta Entidad fue creada por Ley de 18 de diciembre de 1946 con funciones de naturaleza estrictamente urbanísticas: la ordenación urbana de Valencia y sus alrededores. Años más tarde, con fecha 14 de octubre de 1949, se aprobaría el texto de la Ley de ordenación de ese espacio.
} 
nadas organizativas para solucionar los problemas y conflictos territoriales, urbanísticos y medio ambientales de carácter supramunicipal». En plasmación del tal espíritu, el artículo 3 establece que el Consell Metropolitá tiene "como finalidades generales la planificación conjunta y la gestión supramunicipal en las materias de su competencian; esto es, las del «ciclo hidráulico, residuos sólidos, urbanismo, incendios, mataderos, transporte y su infraestructura...".

Conviene en este ámbito llamar la atención sobre una nota, no desconocida a estas alturas para nosotros, que vuelve a convertirse en el principal rasgo distintivo de la Ley de creación de una Entidad supramunicipal en nuestro Derecho: la de la falta de una atribución directa de competencias en favor de los órganos que la integran. La Ley se limita a señalar, de una parte, los círculos materiales sobre los que puede desplegarse la actuación del Área de la Huerta; de otra, la naturaleza de sus funciones sobre ellos; no determina, en cambio, cuál es la cuota concreta de poder que han de desarrollar en cada uno de esos ámbitos. Las funciones de planificación y coordinación, en primer término, serán aquellas que vengan establecidas "en las normas de coordinación en política de ordenación territorial y urbanismo y las que se deriven de las políticas sectoriales del Estado y del Consell de la Generalitat Valenciana»; los servicios supramunicipales, en segundo lugar, los que resulten en aplicación de algunas de las fórmulas establecidas en el artículo 3.4 de la propia Ley: constitución de consorcios o cualquier otra figura asociativa o, en segundo término, de la aprobación del pleno del Consell, previa solicitud de todos los Ayuntamientos afectados. Las competencias del Área metropolitana han quedado, en definitiva, en manos de otras instancias, a cuya labor hemos de estar si queremos realizar una valoración global sobre el papel desempeñado por esta Administración.

No puede hablarse, a estas alturas, de una actuación de la Comunidad Autónoma de Valencia propicia a un trasvase de competencias importantes en favor del Área de L'Horta. Tan sólo pueden destacarse en esta sede el Decreto 103/1988, de 18 de julio y la Ley 1/1991, de 14 de febrero de Ordenación del Transporte en el Área de Valencia.

La primera de las disposiciones citadas, cuya íntegra publicación oficial no se ha producido sino por Decreto de 1 de noviembre de 199349 aprueba las normas para «la ordenación del territorio y la coordinación del planeamiento municipal» en "todos los Municipios integrados en el ámbito territorial del Consejo Metropolitano de L'Horta, o en los que pu-

49 D. O. de la Generalidad de Valencia, n. 2.109 , de 23 de noviembre. 
dieran estarlo en el futuro, y en los que resulten afectados por razones de coherencia urbanística, continuidad territorial o condiciones medio ambientales, como efecto indirecto de la aplicación de estas Normas».

No resulta fácil la síntesis del entero contenido de esas normas de coordinación metropolitana, careciendo, de otra parte, de mayor interés en esta sede. Cabe, tan sólo, destacar el escaso protagonismo otorgado al Consejo metropolitano en beneficio de los órganos de la Comunidad Autónoma, que se convierten así en los verdaderos titulares de los poderes decisorios sobre este espacio. Las funciones del Ente metropolitano quedan reducidas a las de mero informe, "cuando existiere acuerdo mayoritario de los Municipios en la adaptación de sus planes a las directrices» o a las de "propuesta de la solución que resulte más idónea", caso de no existir dicho acuerdo 50 . En definitiva, estas normas de coordinación no constituyen sino un reforzamiento del Área de Valencia; el mismo significado que cabe atribuir a la Ley 1/1991, de 14 de febrero, de Ordenación del Transporte, en la que se hace del Plan de Transportes metropolitano su instrumento básico de actuación y de la Comisión del Plan, órgano de composición mixta en el que se integran representantes de todas las Administraciones implicadas, el ente responsable de su aplicación.

Una posición más favorable al escalón metropolitano es la que se ha detectado, en cambio, en los Municipios de ese espacio geográfico que, valiéndose de diferentes técnicas asociativas, han transferido algunos de sus servicios al Área de la Huerta; pero para tales cometidos, no se crea una Entidad de esta naturaleza.

Una vez más, puede concluirse afirmando la existencia de una nueva Administración Pública, cuyo auténtico valor y sentido termina por desconocerse. ¿Para qué crear una Entidad con lo que ello significa de reduplicación de aparatos burocráticos y de aumento del gasto público si sus funciones no pasan de ser meramente testimoniales, quedando el gobierno real de tales espacios en manos de otras instancias? Como afirmara, no hace mucho tiempo, J. M. BAÑo LEÓN, tiene poco sentido que se constituyan o se permita la constitución de Áreas metropolitanas como corporaciones dotadas de instrumentos personales y materiales y, al mismo tiempo, se impida que esa Área pueda ser titular de los servicios públicos requeridos por la población ${ }^{51}$.

50 Vid. normas 3 y siguientes.

51 "Informe sobre el Área Metropolitana de Valencia" (Le Aree Metropolitane in Europa, Ed. II Mulino, 1994). 


\section{B. El modelo institucional del Área de Barcelona}

La nueva regulación para el Área metropolitana de Barcelona, nacida con la Ley 7/1987, de 4 de abril se asienta en dos Entidades distintas: la Entidad metropolitana del Transporte y la Entidad metropolitana de Servicios Hidráulicos y Residuos sólidos. Dos Administraciones de ámbito territorial diferente y que, además, se superponen a la organización comarcal ya existente, en esa fecha, en todo el territorio catalán.

La primera tiene por fin específico la prestación del servicio de transporte público de viajeros en el área, artículo 15 a); la segunda, la coordinación de los servicios que constituyen su objeto y la realización, establecimiento y prestación de los servicios relacionados con la captación, tratamiento y distribución de agua potable y con el tratamiento y eliminación de las residuales, artículo 17 52. Dos entes de evidente naturaleza institucional a los que el Derecho confiere aquel conjunto de potestades necesarias al cumplimiento de sus fines.

Sin entrar en el examen de los términos concretos de la distribución de competencias que en cada uno de aquellos sectores se opera, importa, a nuestros efectos, destacar la fuerte presencia en ellos de los órganos de la Generalidad. El Plan Intermodal de Transporte, elaborado y aprobado por la Comunidad autónoma, sirve de base al ejercicio de las competencias de la Entidad metropolitana de tal nombre; el Ente de Abastecimiento de Aguas y la Junta de Saneamiento, Entidades creadas por Leyes posteriores a las de institucionalización del nivel metropolitano y dependientes igualmente de la Administración de la Generalidad, asumen, en detrimento, de nuevo, de la Administración metropolitana gestora de esas materias, importantes competencias en cada uno de esos ámbitos.

No resulta fácil, desde tales coordenadas, la valoración global de este modelo. Cualquier pronunciamiento sobre el Área metropolitana de Barcelona exige, además, de un previo análisis del conjunto de Administraciones presentes en ese territorio y de las ideas y opciones políticas que las alumbran. Ello salvado, pueden, no obstante, manifestarse las profundas dudas que razonablemente suscita la eficacia de unas Entidades fuertemente presionadas por la Administración autonómica,

52 La Ley 4/1990, de 9 de marzo, de ordenación del abastecimiento de aguas en el área de Barcelona ha venido a completar el esquema de distribución competencial sentado por esa Ley. 
que chocan, a su mismo nivel, con la Comarca y que se ven igualmente interferidas en el ejercicio de sus competencias por más de una Mancomunidad y empresa pública con funcionamiento en la zona. La disociación de la instancia metropolitana en dos Entidades distintas tampoco contribuye, de otra parte, a un reforzamiento de esta unidad de gobierno ${ }^{53}$.

Los modelos sentados, tanto el de Barcelona, como el de Valencia, distan mucho, en definitiva, de esa Área metropolitana concebida "como Entidad local con competencias propias para resolver los problemas planteados en su escala territorial» que propugnara R. GOMEZ-FERRER muy poco tiempo después de la promulgación de la Constitución ${ }^{54}$.

\section{La realidad metropolitana en otras Comunidades Autónomas}

Junto a estos sistemas metropolitanos que son ya hoy una realidad, puede hablarse también de la existencia de Leyes autonómicas en las que la naturaleza de las Áreas metropolitanas vuelve a quedar indeterminada en espera de la norma concreta que, en su caso, articule cada Entidad de este género. Es lo que ocurre en la Ley 6/1988, de 25 de agosto, de Régimen Local de la Comunidad Murciana que se limita a reproducir la definición de Área metropolitana contenida en el artículo 43 de la LBRL, remitiendo a una posible Ley de constitución la fijación de sus competencias y organización. En la misma línea, se inscribe la D. A. $3 .^{a}$ de la Ley de Comarcas de Aragón en la que se afirma que «en el caso de que por Ley... se cree el Área metropolitana de Zaragoza con el carácter de entidad local podrán corresponder a la misma las competencias atribuidas a la Comarca respecto de su propio ámbito territorial» o el artículo 43 de la Ley 7/1993, de 27 de julio, de Demarcación municipal en Andalucía.

53 Las críticas al actual modelo de gobierno del espacio metropolitano de Barcelona han sido unánimes. Entre otras, pueden verse las formuladas por M. BAssols COMA ( La organización territorial de la Administración de la Generalitat». Autonomies n. ${ }^{\circ}$ 5, 1986, págs. 53 y ss.); R. Martín Mateo ( «Las Áreas metropolitanas». Tratado de Derecho municipal..., ob. cit., pág. 864); ALlENDE LANDA («Áreas metropolitanas. Contenido, crisis y nuevos enfoquesn. Revista Vasca de Administración Pública, n. ${ }^{\circ} 15,1986$ pág. 23); L. Parejo Alfonso ("Barcelona en la nueva organización territorial de Cataluña», REALA, $\mathrm{n} .^{\circ} 233,1987$ ) y J. L. GonzÁlez-Berenguer (Estudios de Urbanismo, Ed. Abella, 1992). Más recientemente pueden verse los comentarios que sobre la situación actual ha realizado J. ToRNos MÁs ("Las ciudades metropolitanas. El caso de Barcelona», Le Aree metropolitane..,, ob. cit., págs. 123 y ss.)

54 «Encaje constitucional de la Administración metropolitana...», ob. cit., pág. 403. 


\section{La valoración del sistema. La falta de institucionalización del nivel de gobierno metropolitano. Las soluciones paralelas}

¿Qué conclusiones permite extraer este conjunto normativo?; ¿puede hablarse, hoy y ahora, de una auténtica institucionalización del gobierno metropolitano en aquellos espacios, que no son pocos, en los que la realidad así lo exige?

Sin duda que la respuesta ha de ser negativa y el balance, por consecuencia, absolutamente pesimista. Esa equivalencia intereses metropolitanos/competencias metropolitanas que debiera inspirar toda la actuación pública en ese ámbito está muy lejos de ser lograda. Si se echa un poco la vista atrás y se observa la situación precedente a 1978 para compararla con la presente, nos encontramos con el siguiente resultado: continúan sin crearse Áreas metropolitanas en superficies de esas características que exigen, por consecuencia, de una respuesta normativa e institucional que satisfaga sus necesidades. Es el caso, en la Comunidad Autónoma de Andalucía por ejemplo, de las Áreas de Málaga, Granada, la Bahía de Cádiz y Sevilla o, fuera de ellas, de espacios tales como los de Zaragoza o los representados por los ejes Oviedo-Gijón y Alicante-Elche; de otra parte, han desaparecido algunas de las existentes a la fecha de promulgación de la Constitución - caso de Bilbao, cuya nueva organización territorial, según se afirma 55 , no ha servido para dar solución a sus problemas o de Madrid, aunque aquí las necesidades del área sí parecen haber entrado en vías de solución ${ }^{56}$-; y c) las Entidades metropolitanas que, por último, se han constituido: las de Barcelona y Valencia, muestran escaso poder y eficacia en su actuación. En el primer caso, por el carácter parcial y fragmentario de las competencias atribuidas a sus Entidades y la fuerte presencia de la Comunidad Autónoma en el gobierno de la zona; en el segundo, por la falta de atribución directa de competencias, característica de la norma que crea la Entidad y una ulterior acción, sin duda cicatera, por parte de los llamados a realizarla.

En conclusión, la fuerte indefinición de la LBRL —que ni siquiera obliga a la creación de Administraciones de este tipo para el gobierno de

55 J. L. IBARRA RoBles (Las Áreas metropolitanas en el modelo autonómico, ob. cit., pág. 117) y R. MARTIN MATEO («El gobierno metropolitano», ob. cit., pág. 25).

56 Así se ha destacado recientemente por T. R. FERNÁNDEZ, para quien Madrid ha encontrado en la creación de la Comunidad Autónoma "«la solución al problema metropolitano que afanosamente vino buscando sin éxito durante cuarenta años» ("Informe sobre el Área metropolitana de Madrid». Le Aree Metropolitane..., ob. cit.). 
los espacios de esta naturaleza- y la escasa y dispar normativa autonómica en este ámbito, no permiten sustentar que el Derecho se haya hecho eco de forma suficiente y eficiente de las necesidades de las grandes aglomeraciones urbanas características de nuestro tiempo y que en España cuentan con no pocas manifestaciones. Una meditación, en suma, sobre el desarrollo de las Áreas metropolitanas en nuestro país conduce, como se ha señalado, a una situación, cuando menos, de incertidumbre ${ }^{57}$.

Ante dicho estado, la solución a los problemas metropolitanos está viniendo por otras vías: las que ofrecen las Mancomunidades de Municipios o la acción sectorial de las Comunidades Autónomas en el ámbito, sobre todo, de la ordenación urbanística. Los Planes de Ordenación del Territorio de las aglomeraciones urbanas del Campo de Gibraltar, Bahía de Cádiz, Málaga, Granada y Sevilla, recientemente aprobados por el Consejo de Gobierno de la Junta de Andalucía ${ }^{58}$, constituyen un buen botón de muestra de esta afirmación.

\section{REFLEXIÓN FINAL}

No resulta ciertamente fácil realizar una valoración de una realidad tan rica y compleja como la que aquí se aborda y cuyas conexiones políticas resultan evidentes. Tampoco tienen por fin estas líneas una reproducción sucinta de las ideas más destacadas que la acción normativa de las Comunidades Autónomas, no siempre inspirada en los mismos principios y con resultados -como hemos visto- muy desiguales en unas y otras, nos pueda inspirar. Esta reflexión quiere situarse en una perspectiva distinta; pretende, en una dimensión estrictamente jurídica, dejar sencilla constancia de cómo se ha desarrollado la actuación de estas Entidades desde 1985 - fecha de promulgación de la LBRL - hasta nuestros días.

Varios datos importantes nos ofrece la propia realidad. Así:

1. El difícil encaje y, por consecuencia, escaso protagonismo de la Comarca en la organización territorial nacida de la Constitución de 1978.

57 A. PÉrez Moreno ("Las Áreas metropolitanas, entre la esperanza y la aporía». $R D U$, n. $\left.{ }^{\circ} 140,1994\right)$.

58 Se trata concretamente de los Acuerdos 10, 17, 24 y 31 de mayo, respectivamente, todos ellos publicados en el BOJA 98, de 30 de junio, a excepción del de la Bahía de Cádiz que se encuentra en el BOJA del día 28 del mismo mes. 
Aunque -como ya expuse en su momento- las regulaciones autonómicas sobre las Comarcas no son del todo coincidentes, el resultado en cuanto a su grado de implantación real es muy similar en todas las Comunidades Autónomas. Las Entidades comarcales cuentan con una escasa participación en la gestión de los intereses públicos, al haber quedado relegadas a la acción futura e incierta de unos Parlamentos que, hasta ahora, no se han caracterizado, precisamente, por su generosidad en la atribución de competencias a estas Entidades; nada garantiza, de otra parte, que vayan a serlo en el futuro.

Las Comarcas creadas no se han erigido realmente en ese escalón territorial, distinto del provincial, para el que fueron concebidas por el Derecho sirviendo, tan sólo, a una prestación asociada de servicios municipales. Un fin que el Derecho no les impide, desde luego, jugar pero para el que el propio ordenamiento jurídico cuenta con otros instrumentos de más fácil realización: las Mancomunidades de Municipios, Consorcios, Entidades de Derecho privado o meros convenios de colaboración interadministrativa. Si a esta falta de virtualidad de la Comarca en aquellas Comunidades Autónomas en las que se ha impuesto, se añade la ausencia de una voluntad política favorable a la creación de esta instancia territorial en esas otras que, como Valencia o Andalucía, cuentan con específica previsión estatutaria al respecto, podrá concluirse que la Entidad comarcal, con los rasgos que de ella predica el Derecho vigente, no termina de encontrar encaje en nuestra organización territorial. Su papel, nítido en el plano de las ideas y en los textos normativos, se encuentra absolutamente difuminado en la realidad, viniendo su lugar a ocuparlo, en no pocas hipótesis, las Mancomunidades de Municipios, Entidad en la que debe, justamente, residenciarse otro aspecto importante de esta reflexión.

2. Que las Mancomunidades de Municipios son las protagonistas estelares del actual régimen asociativo municipal es algo que pocos pueden poner en duda. La realidad, un buen banco de prueba siempre del juego ofrecido por las Instituciones, así lo manifiesta con absoluta nitidez. La relativa facilidad de su procedimiento de constitución asentado en el libre pacto asociativo municipal y despojado, por consecuencia, de los complejos mecanismos de redistribución del poder que acompañan a la creación de otras instancias- y la versatilidad de su objeto - la ejecución de una obra o prestación de un servicio de origen municipal - han convertido a esta Entidad en la fórmula por excelencia de prestación asociada de competencias municipales ante supuestos de insuficiencia o mera conveniencia de los Ayuntamientos en su ejercicio. Hoy y ahora, las Mancomunidades se constituyen en las 
mejores garantes de la supervivencia de los pequeños Municipios y el único cauce posible, a veces, para la resolución de no pocos problemas en las grandes superficies urbanas.

Conviene, sin embargo, llamar la atención sobre un dato en el que quizá no se haya reparado lo suficiente, pero que puede terminar por desvirtuar - si es que no lo ha hecho ya-, no sólo el genuino sentido de esta figura en su configuración histórica, sino, lo que es más importante, el propio valor que la legislación del Estado le otorga. Me refiero a la creciente y progresiva expansión de su objeto. Si la Mancomunidad tradicional tenía por nota distintiva su adscripción a la satisfacción de un fin concreto y determinado; la Mancomunidad de nuestros días es, en la generalidad de los casos, una Entidad abierta a un amplio abanico de competencias de carácter muy heterogéneo. Nada hay, desde el punto de vista jurídico, que objetar a esta Mancomunidad de amplios fines siempre y cuando quede salvaguardado el origen municipal de la obra o servicio que se transfiere; más discutible resulta en cambio, desde estrictas consideraciones de legalidad, el desempeño por esta Entidad de cometidos que trascienden de esa «ejecución de obra o prestación de servicios» -funciones que enmarcan a la figura en la LBRL - para situarse, más bien, en la esfera de las competencias propias de las Comunidades Autónomas. Tal es lo que pudiera estar ocurriendo cuando a las Mancomunidades se atribuyen, por ejemplo, competencias como las de promoción y desarrollo de los recursos de la zona o la ordenación del transporte por carretera en el área.

Desde esta perspectiva, ¿no estaría esa Mancomunidad, al hilo de su más fácil procedimiento de constitución, favorecido, además, por la circunstancia histórica de la uniformidad en la fuerza política gobernante a nivel local, suplantando el papel que la LBRL ha asignado a la Comarca?; ¿no se está, en algunos supuestos, utilizando a la Mancomunidad como respuesta a problemas de ciertos espacios territoriales que tendrían en la Comarca, y conforme al orden legal vigente, su cauce más propio de satisfacción?

La Mancomunidad es, en definitiva, la Entidad llamada por nuestro Derecho a hacer frente a supuestos de insuficiencia municipal o a conseguir servicios más eficaces en su desarrollo y más rentables económicamente; lo que no excluye, a tales fines, el empleo de otras fórmulas alternativas. Lo que ha de considerarse jurídicamente inviable, en el polo opuesto, es el empleo de esta figura para la satisfacción de objetivos que legalmente le excedan. 
3. El gobierno de los espacios metropolitanos continúa, al día de hoy, constituyendo otro de los grandes problemas de la reforma de nuestro mapa local. Son muchas las áreas de tales características que exigen una organización administrativa que resuelva sus innumerables necesidades. Salvo en espacios aislados, no se ha producido en nuestro país una auténtica institucionalización de esta escala de gobierno. Las respuestas a las necesidades de estos ámbitos territoriales están llegando de forma puntual y por otras vías: la que ofrecen las Mancomunidades de Municipios, dotadas, como ocurre, por ejemplo, con la de Bahía de Cádiz, de un altísimo nivel de competencias, o la propiciada por la acción urbanística de las Comunidades Autónomas. El Área metropolitana diseñada por la LBRL no ha sabido, en definitiva, dar respuesta a esa actuación coordinada absolutamente imprescindible para la resolución de las necesidades de dichas áreas.

4. La realidad de nuestro Régimen local muestra, por último, un extraordinario empleo de otras fórmulas de satisfacción de intereses supramunicipales, al margen de las Entidades descritas. Consorcios, Sociedades públicas mixtas y Convenios interadministrativos emergen con fuerza en este sentido.

Parece, en definitiva, como si ninguna de las Entidades diseñadas por la LBRL ocupara el papel que, en principio, esta norma les atribuye. Ante la dificultad del proceso comarcal, las Mancomunidades vienen, en no pocos supuestos, a suplantarlas. En todo caso, la Mancomunidad de objeto puntual y concreto parece superada en beneficio de una nueva Entidad adscrita a la gestión de un conjunto de competencias múltiples y variadas, antesala, quizá, de un proceso más amplio de reordenación de las estructuras locales. Cuando lo que está en juego es la ejecución de una obra o la prestación de un servicio concreto, otras fórmulas parecen mostrar una mayor idoneidad. Ya las indicaba antes: los Consorcios, las Sociedades públicas mixtas y los Convenios interadministrativos. Ello ha hecho, por ejemplo, que la Entidad consorcial, de confusa regulación en la LBRL y cuyo papel parecía, más bien, residual se haya convertido en algunas Comunidades Autónomas en protagonista esencial de su Régimen local. Es el caso, bien significativo, de la Comunidad Autónoma de Andalucía, cuya Ley de Demarcación municipal de 1993 contiene, en su artículo 33.2, una clara decantación en favor de esta Entidad como modo de prestación de los servicios supramunicipales.

Próximo a celebrarse el décimo aniversario de la Ley de Régimen local de 1985, puede afirmarse, en suma, que las ilusiones despertadas 
por un proceso de reforma de las estructuras locales que parecía definitivamente poner fin al uniformismo característico de nuestra planta local, se han visto frustradas.

Resulta, sin duda, difícil adentrarse en las causas que impiden hablar de éxito de la supramunicipalidad en nuestra historia más reciente; entre otras razones, porque son muchos los factores de índole exclusivamente política que subyacen en esa cierta distorsión de las Entidades supramunicipales, conforme a su regulación legal.

Dejando de lado, sin embargo, la dimensión innegablemente política de esta cuestión y la responsabilidad que, por consecuencia, el político haya podido contraer en este ámbito, resulta de justicia reconocer la existencia de algunas causas estrictamente jurídicas que no contribuyen, desde luego, a la implantación de un escalón supramunicipal verdaderamente acorde a las necesidades de nuestro territorio. Sin afán agotador y a modo más de invitación a la reflexión que de opinión cerrada, voy a resumir brevemente algunos de esos motivos que pudieran hallarse en el cierto fracaso o, cuanto menos, atonía, de las Entidades supramunicipales configuradas en los artículos 42, 43 y 44 de la LBRL.

A. Cabe, de una parte, destacar el hecho, de sobra debatido políticamente y analizado con profusión por la doctrina, de la proliferación de instancias sobre un mismo ámbito territorial. El Área de Barcelona constituye en este sentido un ejemplo paradigmático. ¿Pueden ofrecer realmente el juego deseado las instancias presentes en un espacio en el que, además de la Administración del Estado y la de la Comunidad autónoma, conviven Municipios, Diputación Provincial, Comarcas, Entidades metropolitanas, alguna que otra Mancomunidad y más de una empresa pública?

B. En otro ángulo distinto, resulta obligada la mención a la consideración de la Provincia como instancia constitucionalmente indisponible. Al margen de la valoración política que el dato pueda merecer, resulta innegable, en una dimensión estrictamente jurídica, que tal consideración dificulta grandemente la constitución de otros entes supramunicipales, máxime cuando éstos, caso significativo de la Comarca, se presentan con tintes muy parecidos a los de aquellos que dan color a la institución provincial. En la dificultad de encaje de la Entidad comarcal no sólo existe, quizá, falta de voluntad política en las Comunidades Autónomas y oposición, en algunos casos, municipal, sino también, y en no poca medida, recelo a su existencia en las propias Di- 
putaciones Provinciales. Y es que: ¿no son, en último término, dos Administraciones llamadas a desempeñar un mismo papel?; ¿tiene algún sentido su coexistencia?; ¿no pasa, acaso, la implantación efectiva de esa Comarca de corte territorial por la que aboga nuestro Derecho por una suplantación de la instancia provincial?

C. En tercer y último lugar, puede hablarse de la propia dificultad en el proceso de atribución de competencias a las Entidades locales de existencia constitucional no necesaria y a resultas, precisamente, de la garantía con la que, por el contrario, cuentan las Entidades básicas: Municipios y Provincias, a cuyo favor se reconoce un núcleo mínimo de competencias que deberá, siempre, quedar salvaguardado. ¿Puede, acaso, la ley autonómica de creación de una Comarca o de un Área metropolitana disponer la traslación de aquellas competencias en las que se manifiesta, en primer término, la autonomía local -servicios mínimos del artículo 26- sin contar con los titulares de las mismas? El amplio poder de disposición que la LBRL otorga a la ley autonómica ¿no quedará reducido al conjunto de materias expresadas en su artículo 25 , aquellas en las que la medida de la participación municipal en su gestión queda precisamente en manos de la acción de futuros Parlamentos?; ¿qué pasa cuando un Municipio no considere oportuna la cesión de algunas de sus competencias?; ¿puede negarse a tal traslación?

Estas y otras dificultades han hecho, en suma, que Comunidades Autónomas y Municipios, al abrigo además del uniformismo en la fuerza política gobernante en los últimos años, hayan mostrado una importante dejación en la implantación real y efectiva de nuevas instancias territoriales en respuesta a los intereses generales de parte de su espacio, al tiempo que justificarían el éxito, a la par que cierta distorsión, de las Mancomunidades municipales, así como el auge de otras figuras, residuales en la LBRL, en su función de vías de prestación asociada de servicios públicos: los Consorcios; los Convenios interadministrativos e, incluso, otras fórmulas arropadas en el Derecho privado. 
REALA-1994, núm. 264. BARRERO RODRIGUEZ, Mㅡㄹ CONCEPCION. EL JUEGO DE LAS ENTIDADE...

REALA-1994, núm. 264. BARRERO RODRIGUEZ, Mª CONCEPCION. EL JUEGO DE LAS ENTIDADE... 